\title{
Aerodynamic Measurements of a Gulfstream Aircraft Model With and Without Noise Reduction Concepts
}

\author{
Dan H. Neuhart ${ }^{*}$, Judith A. Hannon ${ }^{*}$, and Mehdi R. Khorrami ${ }^{\dagger}$, \\ NASA Langley Research Center, Hampton, Virginia, 23681
}

\begin{abstract}
Steady and unsteady aerodynamic measurements of a high-fidelity, semi-span 18\% scale Gulfstream aircraft model are presented. The aerodynamic data were collected concurrently with acoustic measurements as part of a larger aeroacoustic study targeting airframe noise associated with main landing gear/flap components, gear-flap interaction noise, and the viability of related noise mitigation technologies. The aeroacoustic tests were conducted in the NASA Langley Research Center 14- by 22-Foot Subsonic Wind Tunnel with the facility in the acoustically treated open-wall (jet) mode. Most of the measurements were obtained with the model in landing configuration with the flap deflected at $39^{\circ}$ and the main landing gear on and off. Data were acquired at Mach numbers of 0.16, 0.20, and 0.24. Global forces (lift and drag) and extensive steady and unsteady surface pressure measurements were obtained. Comparison of the present results with those acquired during a previous test shows a significant reduction in the lift experienced by the model. The underlying cause was traced to the likely presence of a much thicker boundary layer on the tunnel floor, which was acoustically treated for the present test. The steady and unsteady pressure fields on the flap, particularly in the regions of predominant noise sources such as the inboard and outboard tips, remained unaffected. It is shown that the changes in lift and drag coefficients for model configurations fitted with gear/flap noise abatement technologies fall within the repeatability of the baseline configuration. Therefore, the noise abatement technologies evaluated in this experiment have no detrimental impact on the aerodynamic performance of the aircraft model.
\end{abstract}

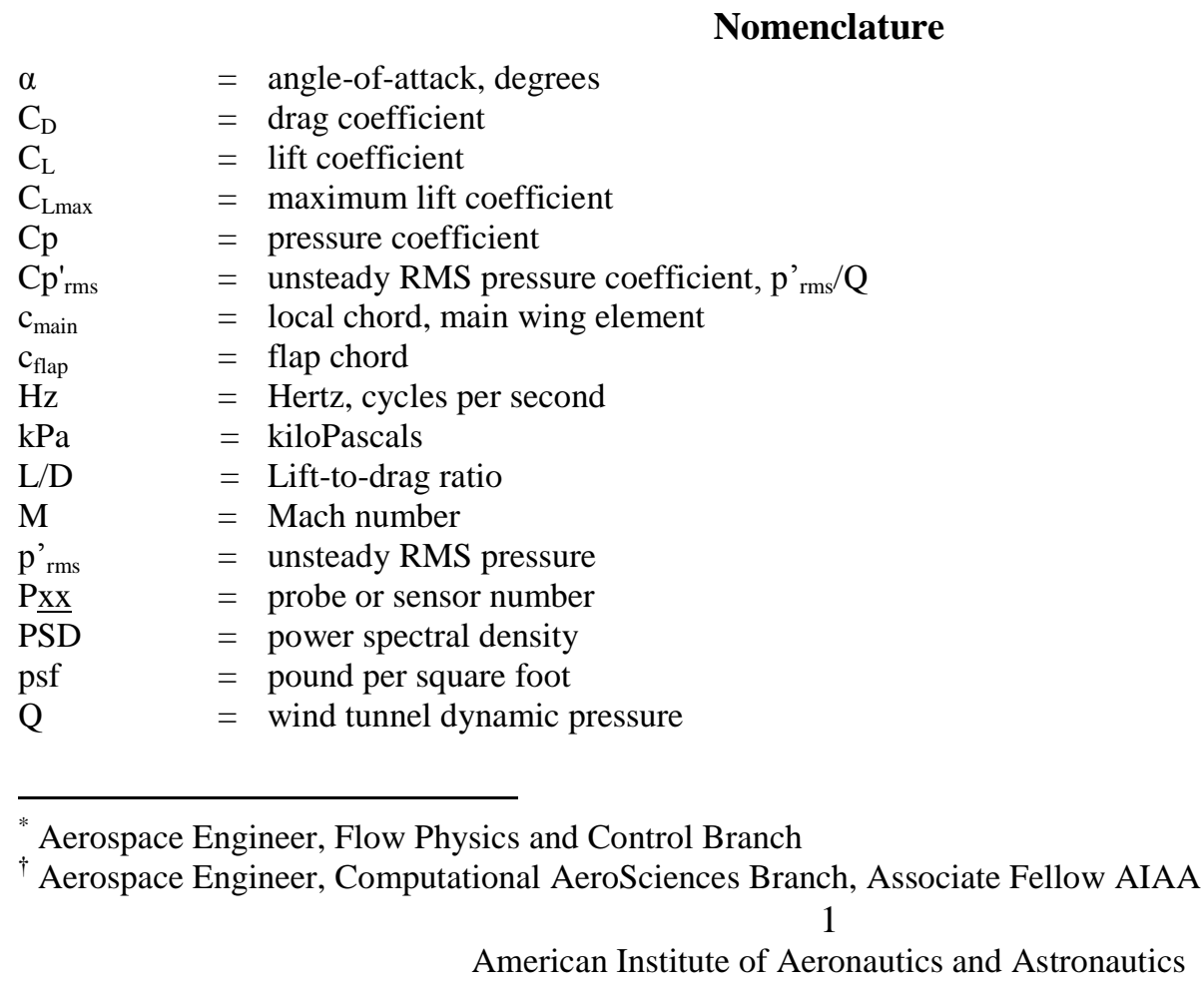




$\begin{array}{ll}\mathrm{Re} & =\text { Reynolds number } \\ \mathrm{rms} & =\text { root mean square } \\ \mathrm{U} & =\text { Uncertainty in measured/calculated quantities } \\ \mathrm{X} & =\text { coordinate along chord } \\ \Delta & =\text { increment in aerodynamic parameter, e.g., } \Delta \mathrm{C}_{\mathrm{L}} \\ \sigma & =\text { standard deviation }\end{array}$

\section{Introduction}

The unprecedented growth of air travel in recent decades, combined with the ever increasing expansion of urban development, have transformed the problem of aircraft noise pollution into an environmental hazard that affects metropolitan areas adjacent to major airports. Steady advances in the reduction of propulsion (jet) noise have pushed airframe noise to the forefront of aircraft noise research and control. The prominent sources of airframe noise are the landing gear and lift-generating devices such as wing flaps and slats. ${ }^{1-10}$ The Environmentally Responsible Aviation (ERA) project of NASA is pursuing the development and maturation of noise reduction technologies that will ultimately confine aircraft noise footprints on the ground within airport boundaries, without detrimental effects to the aerodynamic efficiency of aircraft.

The present effort was accomplished as part of the NASA-Gulfstream partnership for airframe noise research. A series of flight tests and model scale experiments are being executed systematically using a Gulfstream aircraft as the baseline configuration. For the current work, a high-fidelity, heavily-instrumented 18\% scale semi-span Gulfstream aircraft model was used to perform detailed aeroacoustic studies of airframe noise associated with main landing gear/flap components and gear-flap interaction noise, as well as to assess the viability and effectiveness of related noise reduction technologies. The comprehensive set of aerodynamic and acoustic data gathered is being used to increase our understanding of the principles of airframe noise generation, advance and validate simulationbased airframe noise prediction tools, and develop and evaluate efficient noise mitigation strategies/concepts.

Aeroacoustic testing of the $18 \%$ aircraft model was accomplished in a series of carefully-planned entries in the NASA Langley Research Center (LaRC) 14- by 22-Foot Subsonic Tunnel (14x22). The first entry, lasting four weeks, was completed in November of 2010. The test was devoted to mapping the aerodynamic characteristics of the sub-scale model. During that entry, in addition to acquiring the global forces (lift and drag), steady and unsteady surface pressure measurements were obtained. A full account of the aerodynamic results obtained during the 2010 test was presented in Refs. 11 and 12. The second $14 \times 22$ tunnel entry, lasting five weeks, was concluded in late March of 2013. This segment was dedicated to extensive aeroacoustic testing of the model in landing configuration without (baseline) and with flap/gear noise reduction devices installed. During this entry, aerodynamic and acoustic measurements were conducted simultaneously. To reduce the impact of background noise and improve the quality of the collected acoustic data, the $14 \times 22$ tunnel was operated in its open-jet (walls up) acoustic configuration whereby the test section floor, raised ceiling, and test chamber walls were treated with sound absorbing foam wedges. The third entry, lasting four weeks and directly following the second entry, was completed in late April of 2013. Employing Particle Image Velocimetry (PIV) and Laser Doppler Velocimetry (LDV) techniques, this final test was dedicated to acquiring off-surface flow measurements from the $18 \%$ model baseline landing configuration with special attention paid to documenting gear-flap flow interaction.

The present paper is focused on the steady and unsteady aerodynamic measurements. Details of the acoustic data and off-surface PIV measurements are given in companion papers by Khorrami, et al. ${ }^{13}$ and Yao, et al. ${ }^{14}$, respectively.

\section{Aircraft Model and 14x22 Wind Tunnel}

The test bed was an $18 \%$ scale semi-span, high-fidelity replica of a Gulfstream aircraft (see Fig. 1). It was designed, fabricated, instrumented, and integrated at NASA LaRC based on a set of geometry files provided by Gulfstream. The model comprises a fuselage, wing, flap, flow-through nacelle, pylon, and main landing gear. From nose to tail, the model is 185.4 in $(4.709 \mathrm{~m})$ long. The wing span (measured from the wind tunnel floor to the tip of the winglet) is 104.5 in $(2.654 \mathrm{~m})$. A full account of the model development effort, including its fabrication, 
instrumentation, and integration is given in Refs. 11 and 12. To evaluate the acoustic performance of several noise reduction concepts for landing gear, a duplicate of the main landing gear of the $18 \%$ scale semi-span model was produced under a separate partnership between NASA and Goodrich Landing Gear Services. For identification purposes, the two main gear models will be referred to as the original gear and the Goodrich gear.

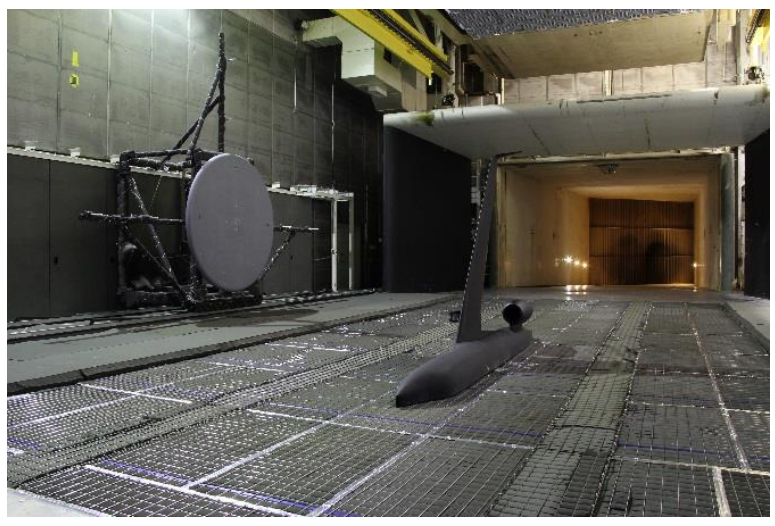

a) Installed in NASA LaRC $14 \times 22$ tunnel.

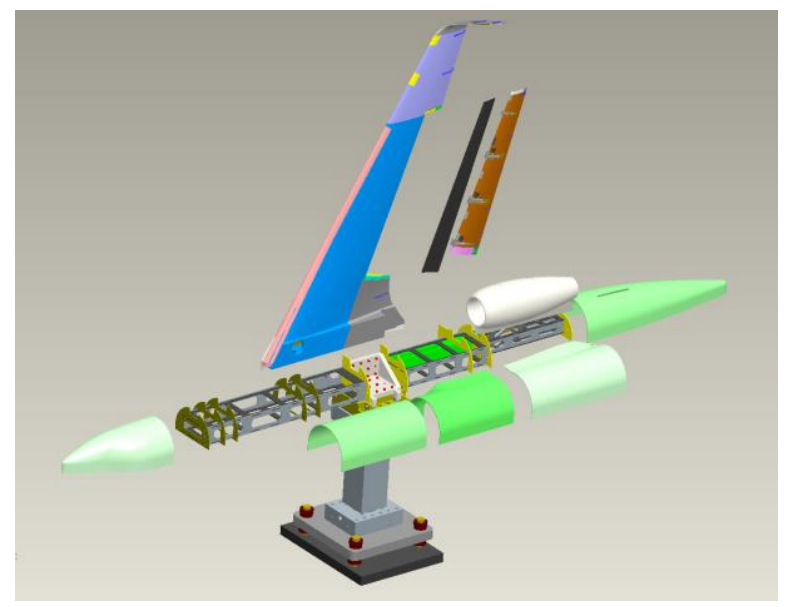

b) Exploded view.

Figure 1. 18\% scale semi-span Gulfstream aircraft model.

\section{A. Model Steady Pressure Port and Unsteady Pressure Transducer Locations}

A detailed description of the $18 \%$ scale model instrumentation is provided in Refs. 11 and 12 . To facilitate presentation of the 2013 aerodynamic results, a brief overview of the steady and unsteady pressure measurement locations is given here. In total, 758 static pressure ports with 0.020 in $(0.5 \mathrm{~mm})$ inner diameter, 69 miniature unsteady pressure transducers, and 12 accelerometers were installed on the model. Of the total static ports, 345 were placed on the wing in eight full rows, two partial rows, and two full rows on the winglet. Two hundred and fifty four (254) static ports were placed on the flap, unevenly distributed among eleven rows. To resolve the finer details of the surface pressure features at the flap inboard and outboard tips, a larger number of orifices was concentrated in these areas. There were 105 static orifices installed on the main landing gear. The distribution of ports on the various gear subcomponents is as follows: 32 on each wheel, 23 combined on the two main struts, and 18 on the door. There were 54 pressure ports on the fuselage, arranged in two circumferential rows and one nearly streamwise row that was intended for capturing wing-body juncture effects.

Of the 69 dynamic sensors, 40 were installed on the flap. To cover the regions of high amplitude pressure fluctuations, the transducers were distributed in three distinct areas: two narrow chordwise strips adjacent to the flap inboard and outboard edges, and along the mid-span section, subsequently referred to as the main body of the flap. To capture the unsteady pressure field associated with the gear-flap flow interaction as well as the vortex roll-up process, the inboard flap edge was populated with the highest concentration of dynamic pressure sensors. Given the importance of the edge sidewall on vortex system inception, four sensors were installed on the sidewall itself. In total, 29 sensors were installed on the main landing gear components.

\section{B. Model Force Balance}

To obtain accurate measurements of lift and drag, the semi-span model was designed to couple with the NASA LaRC VST-8 strain gauge balance. The VST- 8 has a capability of 5,000 pounds of normal force and an accuracy of $0.23 \%$ full scale. Because of the way the model was mounted, its axial force was actually measured by the side force of the balance, which has a capability of 1,500 pounds and an accuracy of $0.16 \%$ full scale. 


\section{14x22 Wind Tunnel Acoustic Configuration}

Acquisition of acoustic measurements and determination of the flyover directivity patterns for flap/gear noise sources required that the $14 \times 22$ facility be operated in its open-jet mode, whereby the ceiling and the side walls of the tunnel test section are raised. The suitability of the tunnel open-jet mode for aeroacoustic testing was determined during the 2010 entry $^{11,12}$, when it was demonstrated that the overall aerodynamic characteristics of the $18 \%$ scale model remained unaffected regardless of whether the measurements were conducted with the test section in the closed-wall or open-wall (open-jet) mode. For the 2013 entry, in order to diminish the tunnel background noise levels and improve the quality of the measured acoustic data, the $14 \times 22$ test section was operated in its acoustic mode. In this configuration, the test section floor, raised ceiling, and the test chamber side walls were treated with sound absorbing foam (see Fig. 1a). The acoustically soft test section floor was a very rough, non-uniform surface compared to the $14 \times 22$ standard rigid floor. It was anticipated that the roughened surface may significantly thicken the turbulent boundary layer on the floor, thus affecting the aeroacoustic measurements.

\section{Results}

The second entry into the LaRC $14 \times 22$ wind tunnel was completed in late March 2013. This entry was devoted to simultaneous aerodynamic and acoustic measurements. Given the specific interest in airframe noise during landing operations, the $39^{\circ}$ flap setting with the main landing gear on and off were the most heavily tested configurations of the experiment. To deduce some of the scaling laws associated with the fluctuating surface pressure and radiating acoustic fields, measurements were obtained at Mach numbers of $\mathrm{M}=0.16,0.20$, and 0.24, with 0.2 representing the nominal speed at which the majority of the measurements were performed. Results for this baseline $\mathrm{M}=0.2$ setting are presented here. A detailed presentation of the collected dataset, including the effects of noise reduction technology on the aerodynamic performance of the $18 \%$ model, is provided.

\section{A. Test Conditions}

Most of the data were acquired for a nominal Mach number of $M=0.2$. At this speed, the tunnel dynamic pressure, $\mathrm{Q}$, and the freestream speed are approximately $57 \mathrm{psf}(2.72 \mathrm{kPa})$ and $225 \mathrm{ft} / \mathrm{sec}(68.6 \mathrm{~m} / \mathrm{sec})$, respectively. The corresponding unit Reynolds number is $1.341 \times 10^{6} / \mathrm{ft}\left(4.400 \times 10^{6} / \mathrm{m}\right)$ resulting in a Reynolds number of $3.442 \times$ $10^{6}$ based on the $18 \%$ scale model mean aerodynamic chord of 30.8 in $(0.782 \mathrm{~m})$. The freestream turbulence level in the $14 \times 22$ tunnel with the facility in the open-jet configuration is on the order of $0.25 \% ;^{15}$ there is no information on flow turbulence when the facility is operated in the open-jet acoustic configuration mode.

\section{B. Lift and Drag Forces}

Sample plots of the measured lift $\left(\mathrm{C}_{\mathrm{L}}\right)$ and drag $\left(\mathrm{C}_{\mathrm{D}}\right)$ coefficients for the baseline configuration (flap at $39^{\circ}$, main landing gear on) are plotted in Fig. 2. As shown in the lift curves of Fig. 2a, for the open-jet data from the 2010 test (test 593, hard floor) and the open-jet data from the 2013 test with the acoustically soft surfaces (test 604, acoustic floor), there is an apparent loss of lift due to the treatment. In contrast, if one compares the 2010 lift curve with the 2013 lift curve for the untreated (hard) floor (test 604, hard floor), the lift data are in close agreement. This leads to the conclusion that the acoustic treatment on the floor was the main contributing factor in the loss of lift. The most likely cause was the expected thicker boundary layer over the much rougher floor surface with the acoustic treatment (see Fig. 1a). The thicker lines in Fig. 2 are the prediction intervals based on data repeatability for the baseline configuration and will be discussed further in the following paragraphs. The corresponding effects on drag are shown in Fig. 2b. Similar trends as those of Fig. 2a are also observed in this figure - the 2010 and 2013 data for the hard floor compare favorably, but the results for the acoustically-treated floor show an effect on the drag. Thus, we believe that the acoustically-treated floor, and not the acoustically-treated walls and ceiling, was responsible for the change in the model force data. Steady pressure data presented later in this paper will substantiate this conclusion.

During the aeroacoustic and PIV tests we took a closer look at data repeatability for the baseline configuration. Only measurements up to stall were used. We employed the statistical analysis method of regression described and used by Wahls, et al. ${ }^{16}$ This approach uses a least squares polynomial curve fit based on all the data points. The order of the curve fit was determined through minimization of the residuals between each data point and the curve fit ( $3^{\text {rd }}$ order was chosen). The data scatter range was assessed by using the concept of prediction intervals to determine 
the bounds about the curve fit. These prediction intervals indicate that for a certain confidence level, any future data

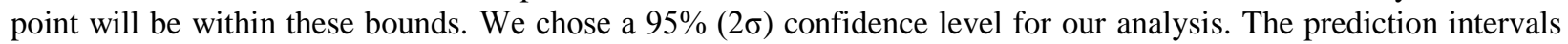
were also compared to a pre-test uncertainty analysis. This analysis was based on instrumentation uncertainties and repeatability of the tunnel test section condition measurements ${ }^{17}$ and considered precision errors only. Then propagation of errors was used through the data reduction equations.

Data repeatability during the aeroacoustic test will be addressed first. There were four runs for the baseline configuration spread throughout the test. Fig. 3 a shows the results of the repeatability analysis for $C_{L}$ vs. $\alpha ; \Delta C_{L}$ is the difference between each data point and the curve fit and is shown as a percent of $\mathrm{C}_{\mathrm{L}}$. Fig. $3 \mathrm{~b}$ and $3 \mathrm{c}$ show $\Delta \mathrm{C}_{\mathrm{D}}$ (\%) and $\Delta \mathrm{L} / \mathrm{D}(\%)$, respectively, as functions of $\alpha$. As expected, these figures show the prediction intervals to be of the same order of magnitude as the uncertainty estimate. In this case, the prediction intervals are smaller than the uncertainty analysis indicated.

The residual plots indicate that the data scatter is not all random; thus, biases are easier to find. For example, in Fig. 3a, run 21 shows slightly lower $C_{L}$ over the angle-of-attack range than the rest of the runs; in Fig. $3 b$, it shows a slightly lower $\mathrm{C}_{\mathrm{D}}$. This run was performed with the original landing gear installed; the other three runs used the Goodrich landing gear instead. This bias might be due to the different landing gear, but because run 21 is within the same uncertainty limits and prediction intervals as those with the Goodrich gear, from a statistical viewpoint we cannot distinguish between them.

Data repeatability results for the PIV test (acoustic floor removed and standard hard floor in place) are shown in Fig. 4. Six runs were used for the analysis. Fig. 4a through $4 \mathrm{c}$ show $\Delta \mathrm{C}_{\mathrm{L}}(\%), \Delta \mathrm{C}_{\mathrm{D}}(\%)$, and $\Delta \mathrm{L} / \mathrm{D}(\%)$, respectively, as functions of $\alpha$. Again, the prediction intervals for the three parameters of interest are within their corresponding uncertainty levels .

The data repeatability analyses for the aeroacoustic test (acoustic floor) and the PIV test (hard floor) confirm that the differences in $C_{L}$ (Fig. 2a) and $C_{D}$ (Fig. 2b) are statistically significant and outside of the scatter for each individual test, as seen by the fact that the prediction intervals for each test (shown by the thickened lines) do not overlap.

Another important use of the aeroacoustic repeatability analysis is to determine if different noise reduction concepts have a significant effect on the global aerodynamic model forces. All aerodynamic runs with noise reduction concepts installed, on flap edges, main landing gear, or both, will now be discussed. One concept for the flap edges, FLEXSEL (FLEXible $\underline{\text { Side E}}$ Edge Link, see Fig. 5), stood out aerodynamically. This structural-link design uses stretchable (hyper-elastic) materials for linking the flap side edge to the nearest wing edge. The transition/linkage occurs rapidly over a very short distance (less than $2 \%$ of flap span) without the need to produce lift from the linkage surface. Both elastic and rigid versions of the concept were tested. Figure 6 a displays $\Delta \mathrm{C}_{\mathrm{L}}(\%)$ vs. $\alpha$ for all the noise reduction concepts relative to the baseline configuration curve fit from the aeroacoustic test. Prediction interval lines for the baseline configuration are also included in the figure. None of the concepts show a negative impact on the lift performance of the model. FLEXSEL (runs 192 through 198) provides a statistically significant increase in $C_{L}$ relative to the baseline configuration. Runs 192, 193, 194, 195, and 198 were all performed with the rigid, 100\% chord FLEXSEL concept with and without various noise reduction fairings applied to the landing gear. The behavior for runs 194,195 , and 198 shows a consistent $C_{L}$ increment over the entire angleof-attack range. Runs 192 and 193 (acquired the previous day) show a decrease in this trend at higher angles of attack. Since runs 193 and 195 are for identical configurations (repeat runs), the reason for the difference in their behavior is unknown. Figure $6 \mathrm{~b}$ shows the effect on $C_{D}$ of the various concepts. It is difficult to draw any firm conclusion from this plot. Figure $6 \mathrm{c}$ shows the effect of the concepts on L/D. Some of these concepts show a slight increment in $\mathrm{L} / \mathrm{D}$ as compared to the baseline.

The residual plots only contain data prior to stall. Figure 7 presents the $\mathrm{C}_{\mathrm{L}}$ vs. $\alpha$ behavior, including the stall region, for the baseline configuration (run 150), a typical FLEXSEL configuration (run 195), and a different noise reduction concept chosen at random (run 186). FLEXSEL shows a consistent, measureable $\mathrm{C}_{\mathrm{L}}$ increase until stall. During this particular run, stall occurred at the same angle of attack as the baseline, but at a slightly higher $\mathrm{C}_{\mathrm{Lmax}}$. For other FLEXSEL runs (not shown), the model stalled at a slightly lower $\alpha(\sim 0.25$ degrees), but reached the same $\mathrm{C}_{\mathrm{Lmax}}$ as the baseline configuration before stalling. The other noise reduction concept, porous flap tips, has a lift curve very similar to that of the baseline configuration. 


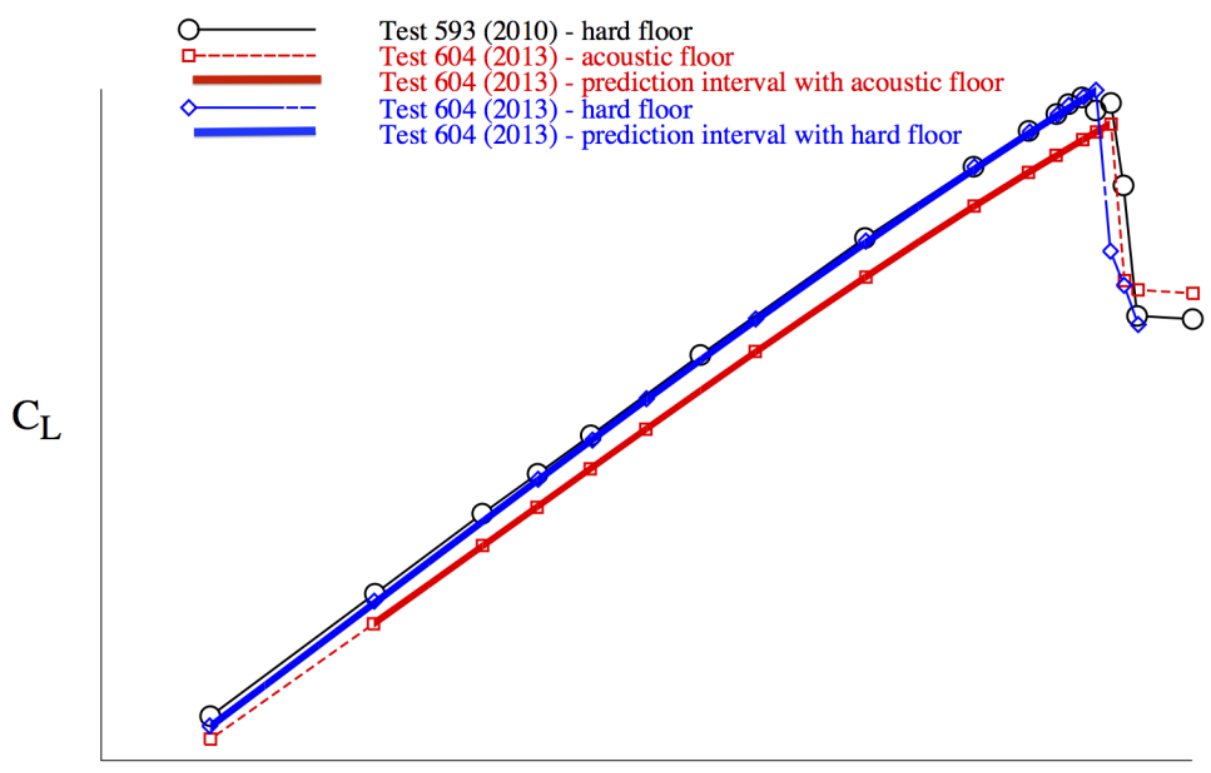

$\alpha$

a) Lift coefficient, landing gear on, flaps $39^{\circ}$.

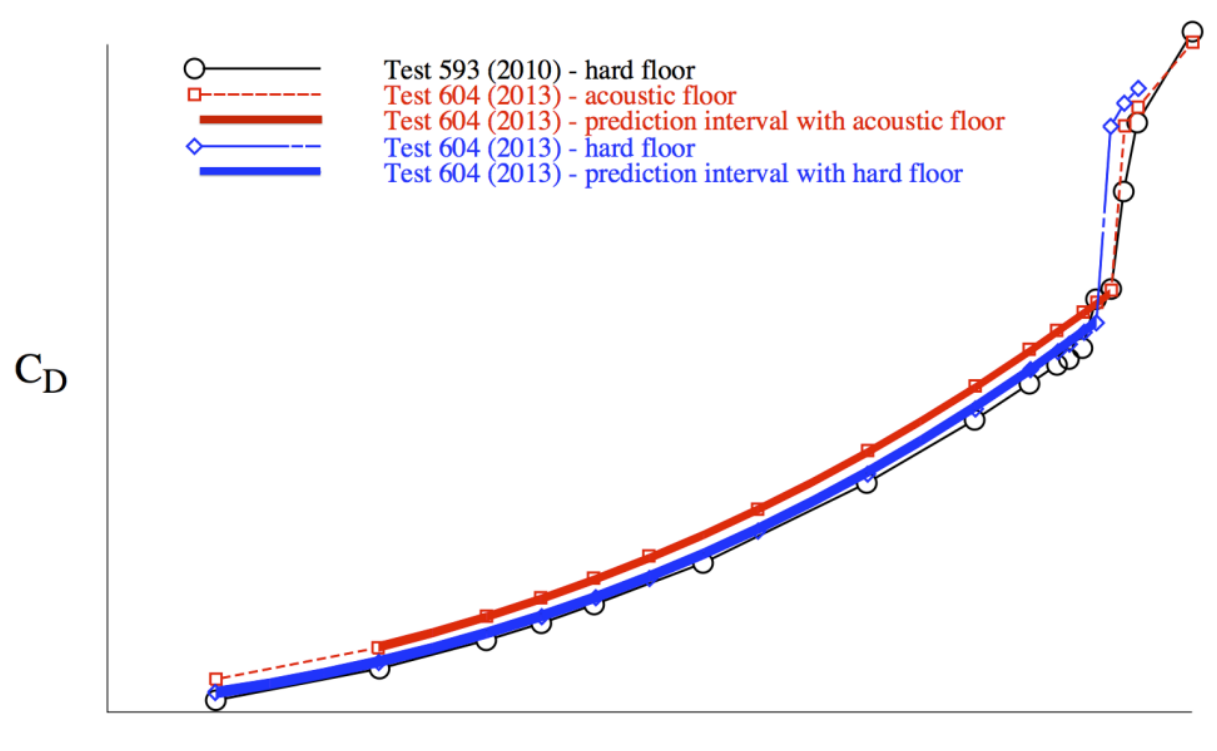

$\alpha$

b) Drag coefficient, landing gear on, flaps $39^{\circ}$.

Figure 2. Variation of lift and drag coefficients with angle-of-attack. 


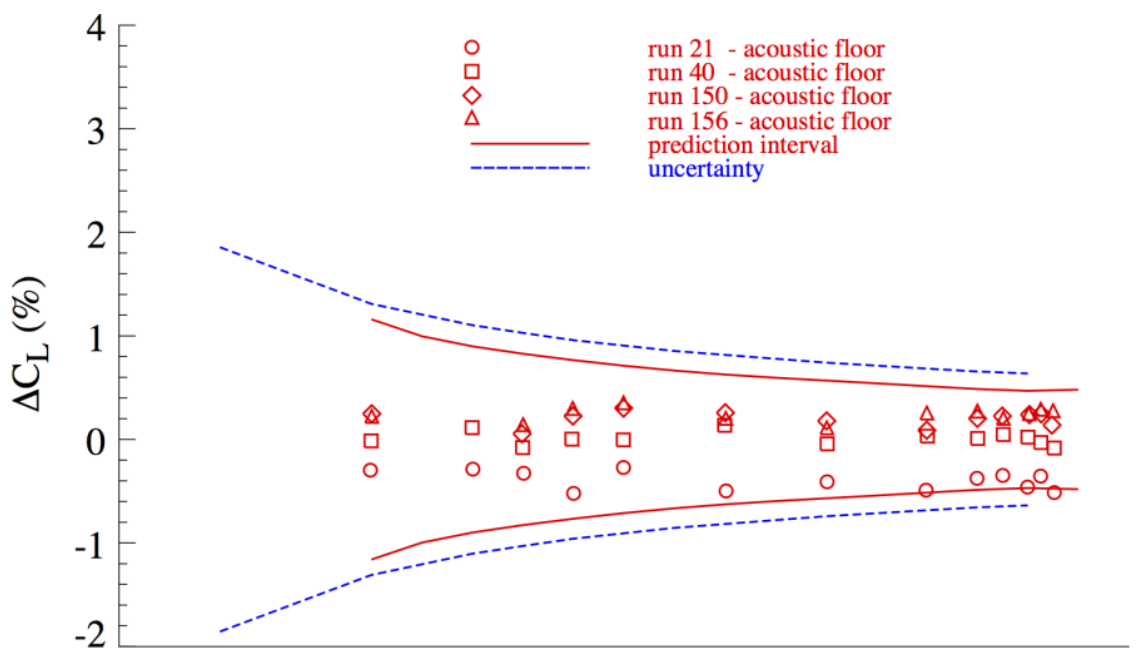

$\alpha$

Figure 3a. Repeatability analysis for the baseline configuration with acoustic floor in place- $C_{L}$ vs. $\alpha$.

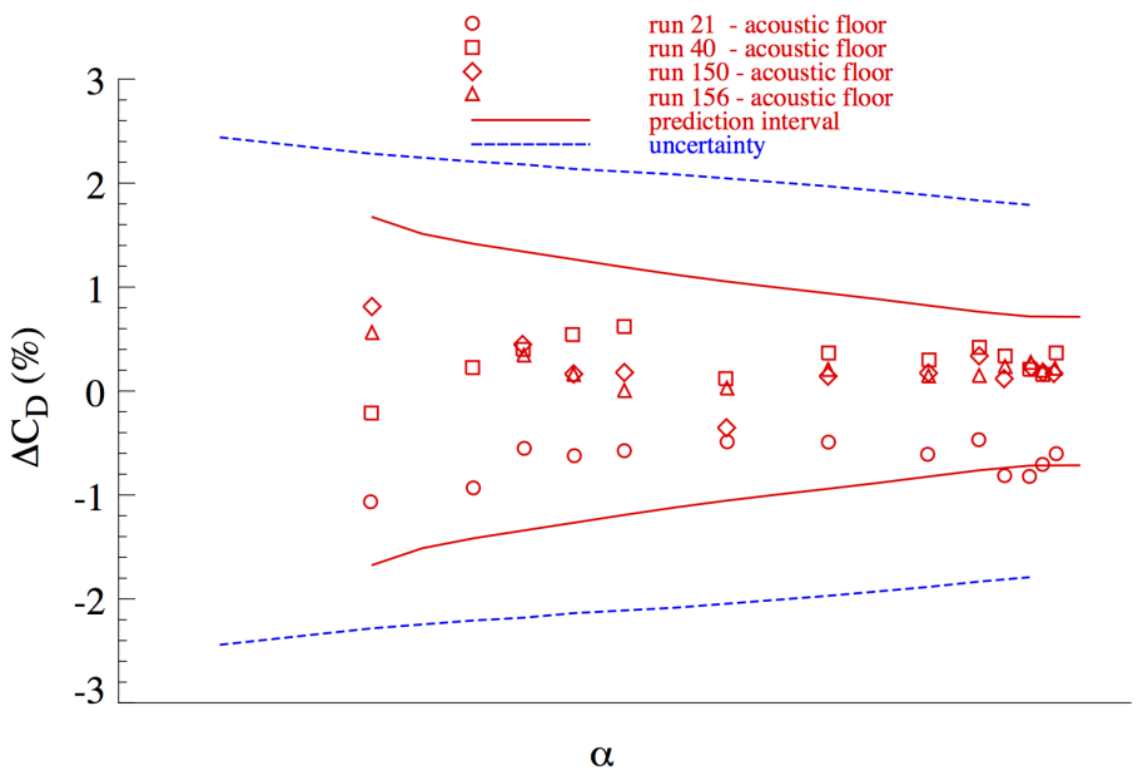

Figure 3b. Repeatability analysis for the baseline configuration with acoustic floor in place- $C_{D}$ vs. $\alpha$. 


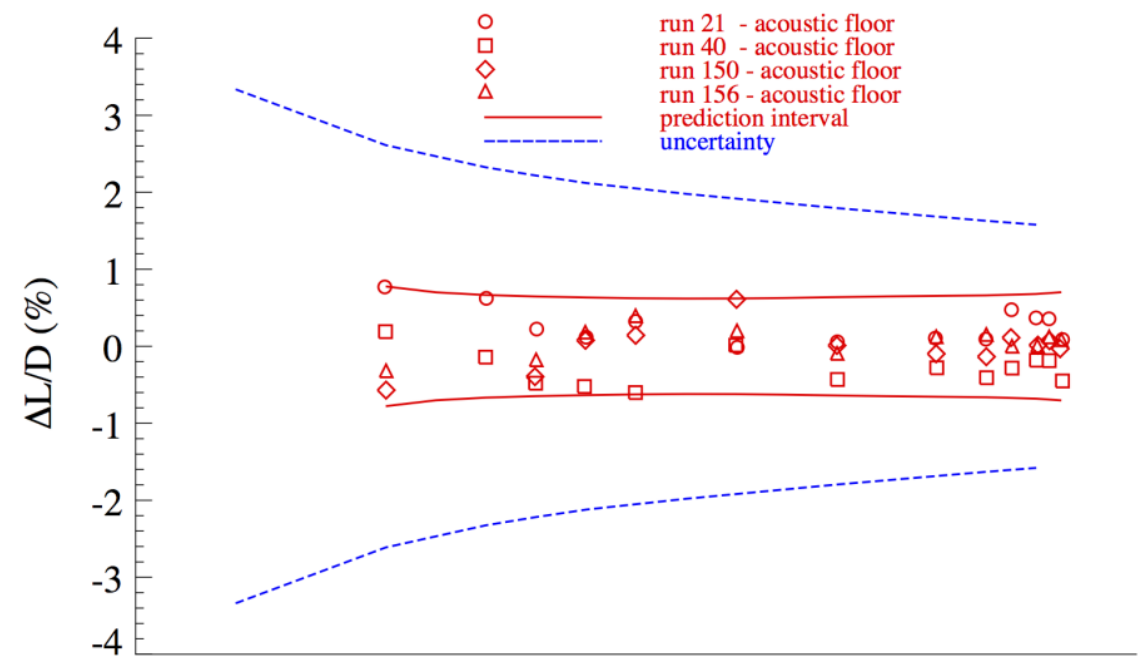

$\alpha$

Figure 3c. Repeatability analysis for the baseline configuration with acoustic floor in place-L/D vs. $\alpha$.

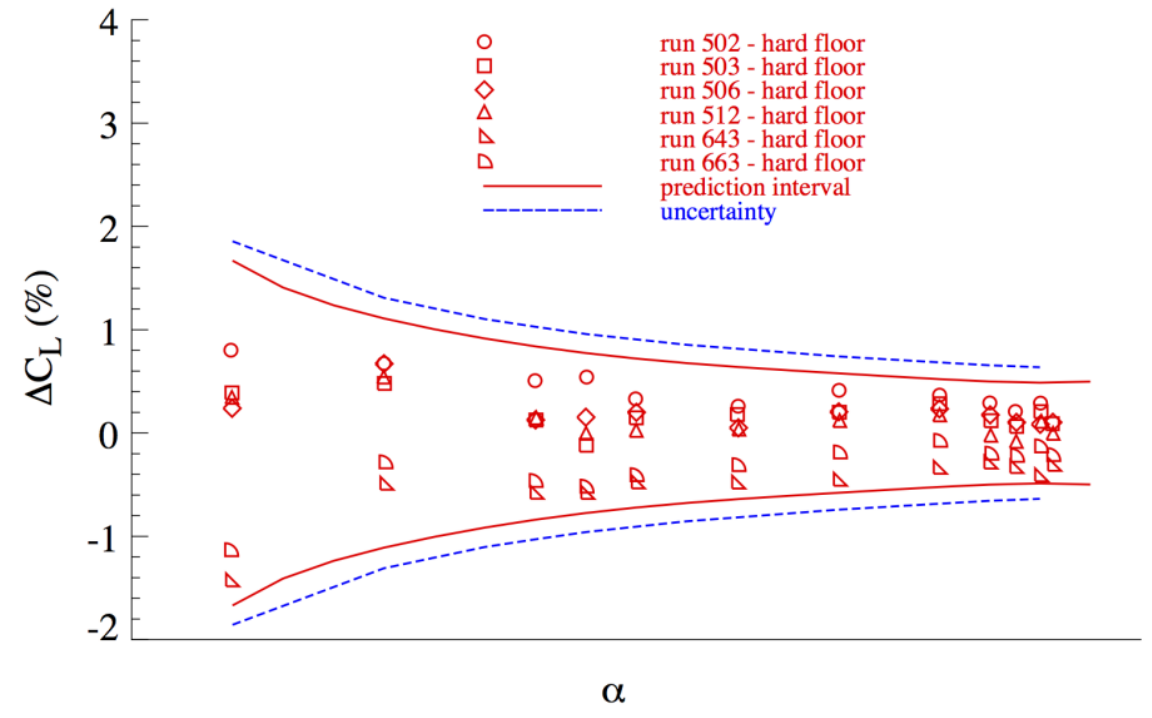

Figure 4a. Repeatability analysis for the baseline configuration with hard floor in place- $C_{L}$ vs. $\alpha$. 


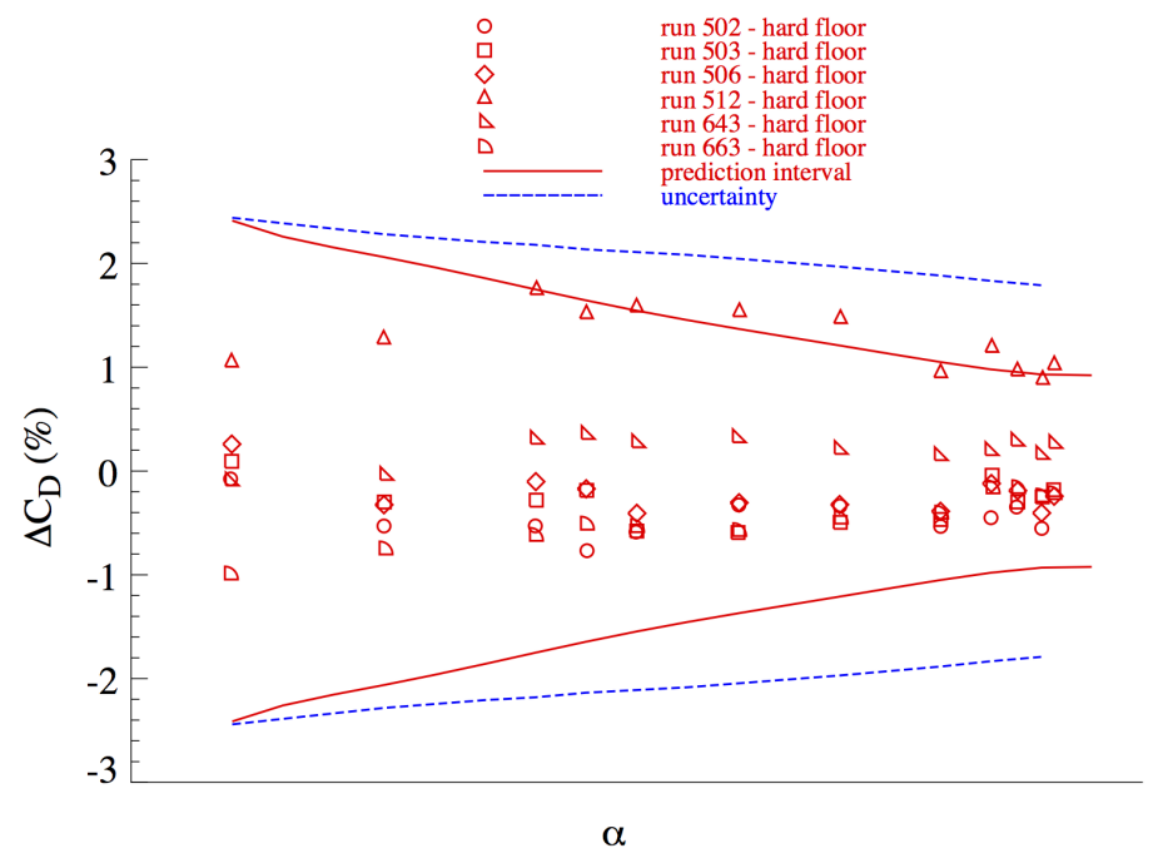

Figure 4b. Repeatability analysis for the baseline configuration with hard floor in place- $C_{D}$ vs. $\alpha$.

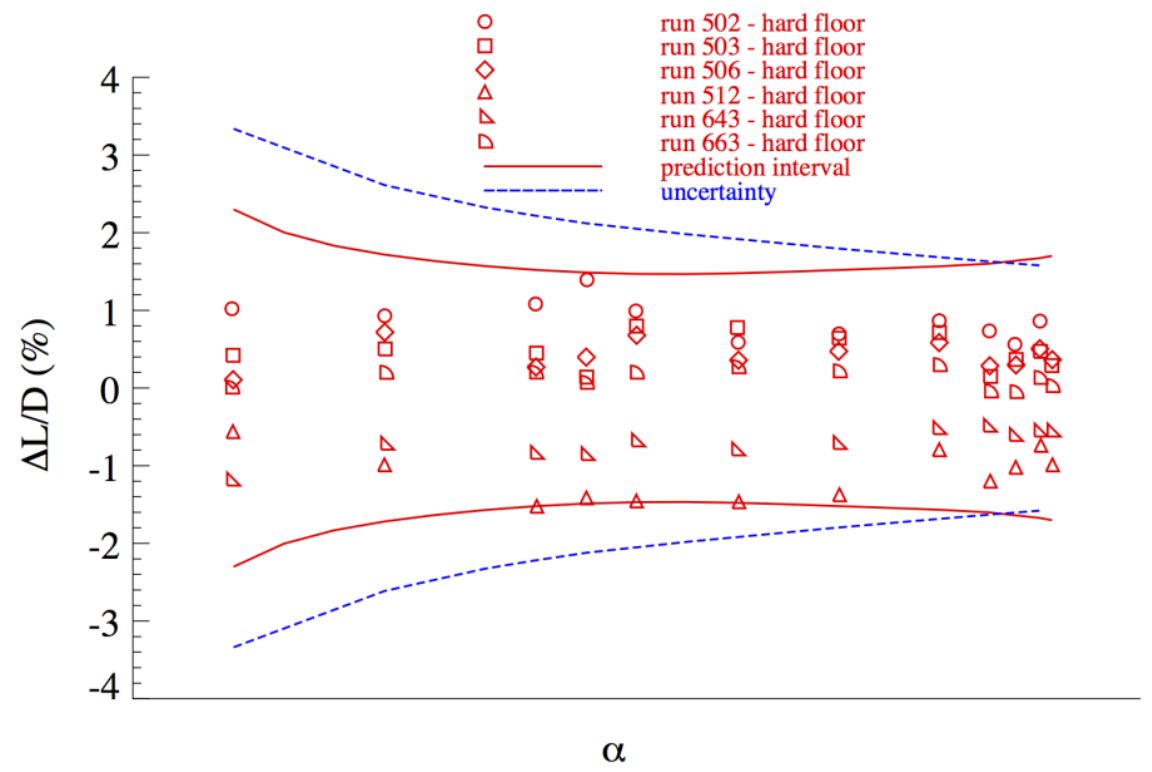

Figure 4c. Repeatability analysis for the baseline configuration with hard floor in place-L/D vs. $\alpha$. 


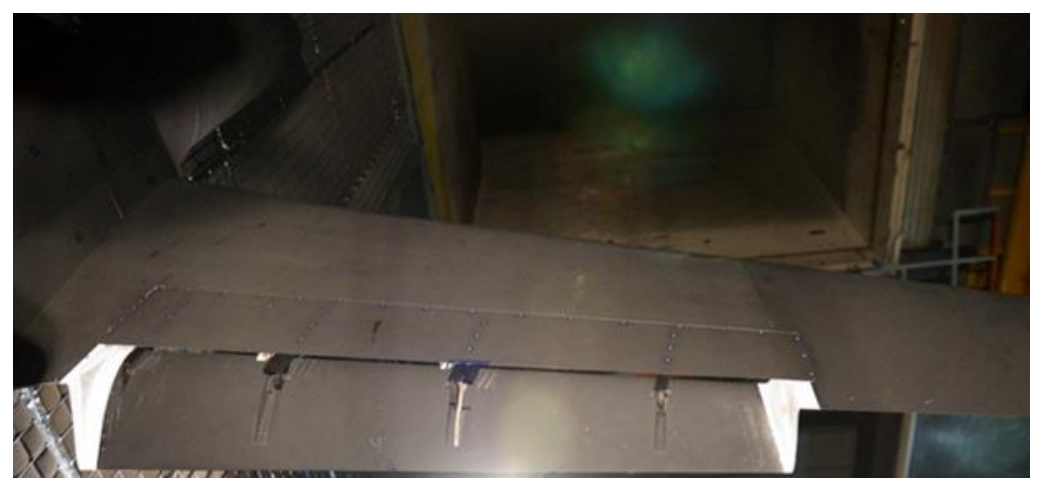

Figure 5. FLEXSEL concept as installed on $18 \%$ scale Gulfstream aircraft model flap.

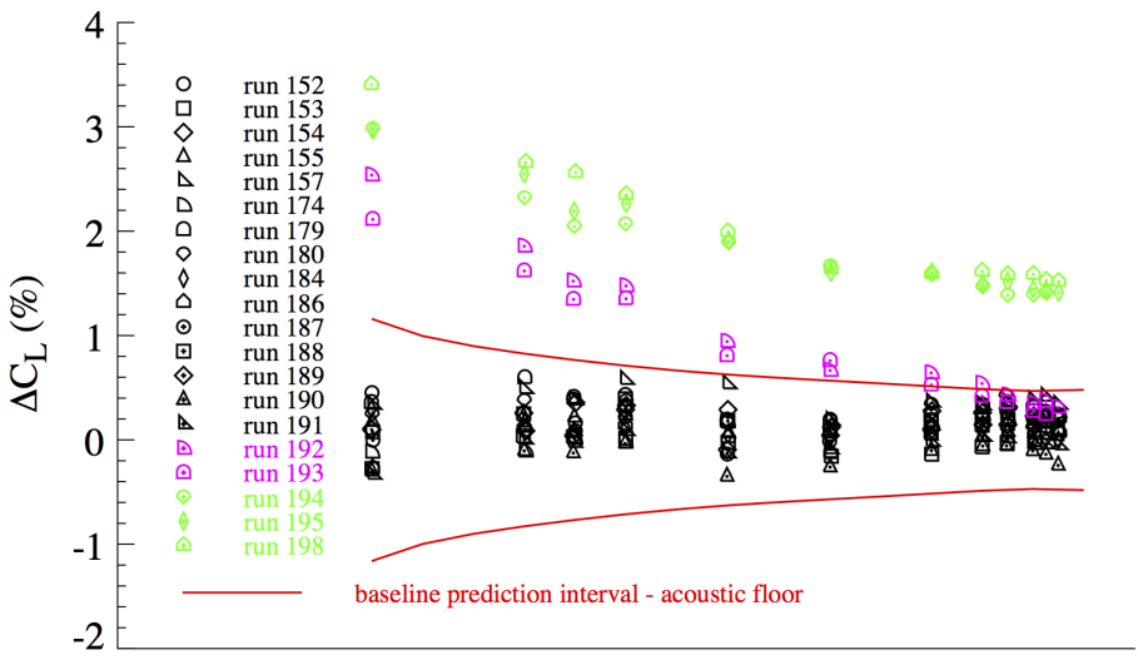

$\alpha$

Figure 6a. Repeatability analysis for noise reduction configurations- $C_{L}$ vs. $\alpha$. 


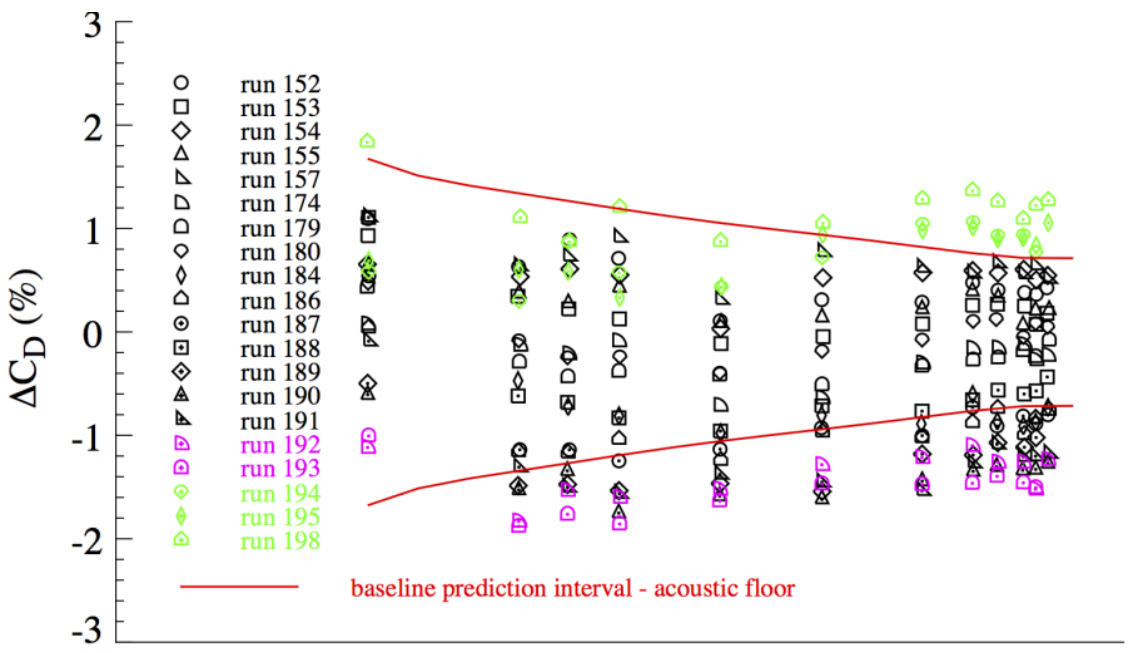

$\alpha$

Figure $6 b$. Repeatability analysis for noise reduction configurations- $C_{D}$ vs. $\alpha$.

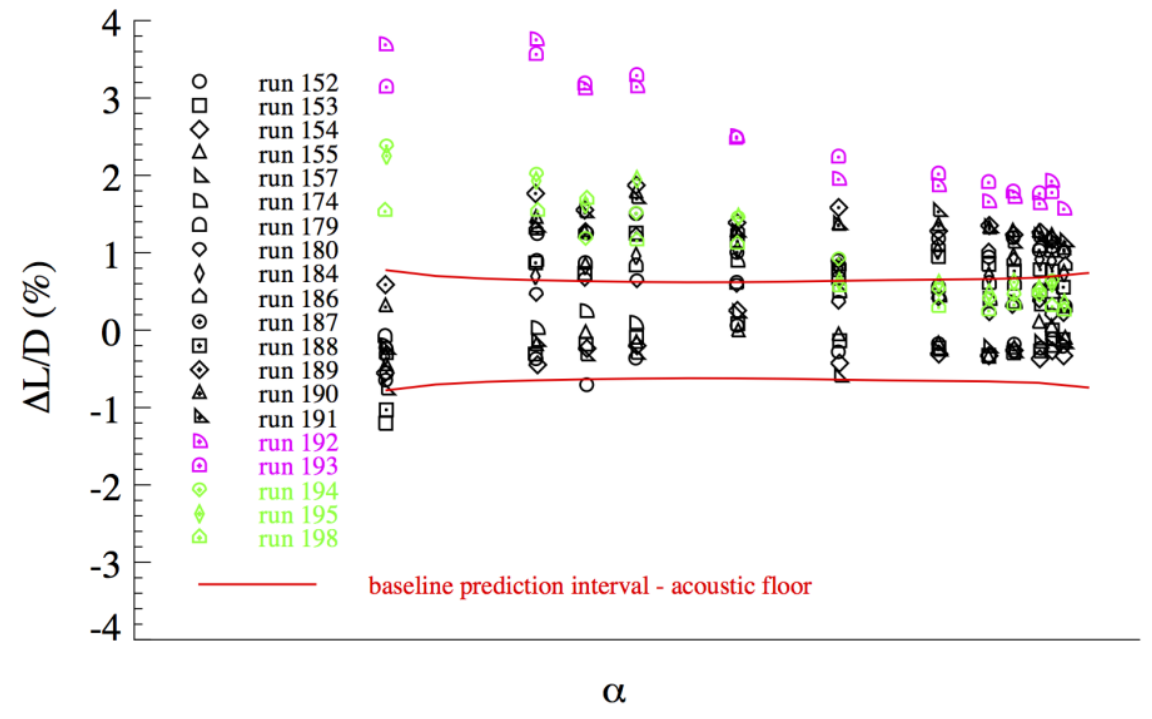

Figure 6c. Repeatability analysis for noise reduction configurations-L/D vs. $\alpha$. 


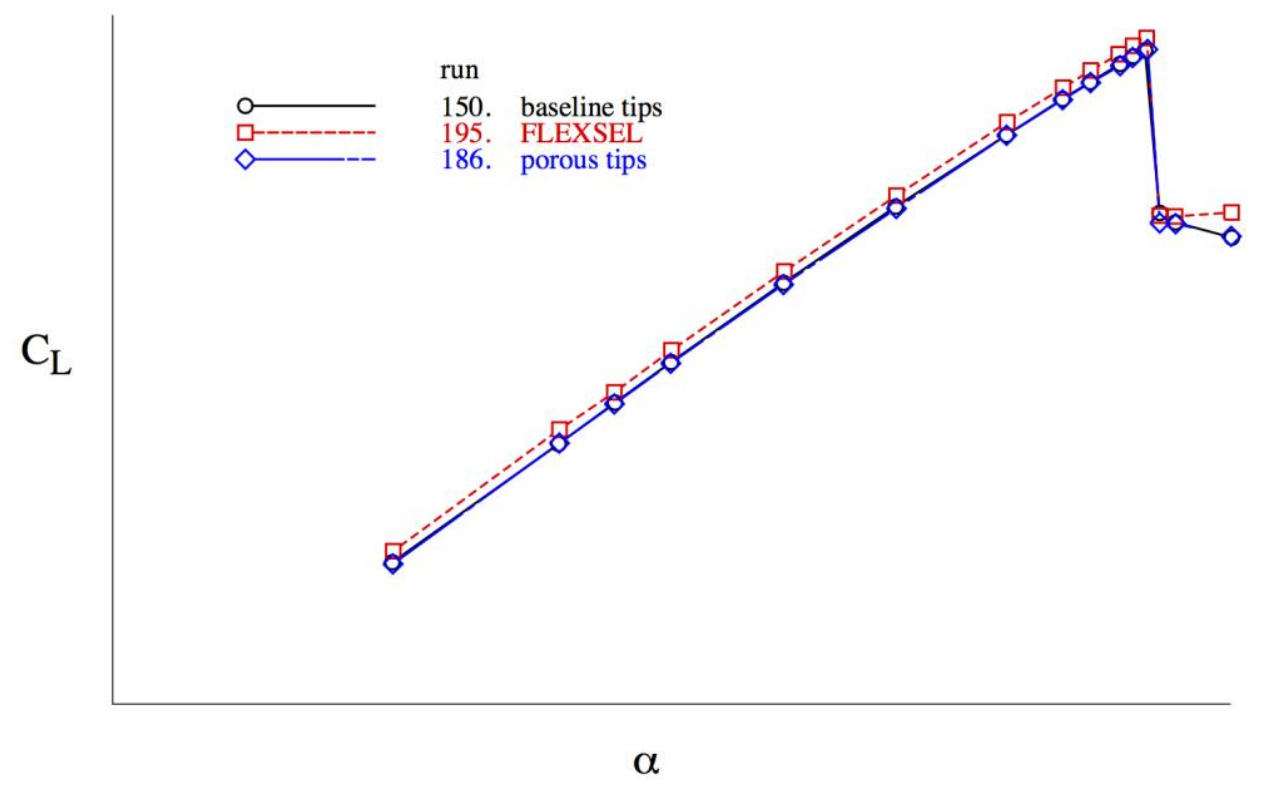

Figure 7. $\mathrm{C}_{\mathrm{L}}$ vs. $\alpha$ for the baseline configuration and two flap noise reduction concepts.

\section{Steady Surface Pressures}

In an attempt to find the fluid-mechanical source of the lift loss that occurred while using the acoustically-treated floor (see Fig. 2a), sample plots of steady pressure variation over the wing and flap for $\alpha=3^{\circ}$ are now discussed. Wing and flap pressure row locations are given in Figs. $8 \mathrm{a}$ and $8 \mathrm{~b}$, respectively. The comparison is made between the open-jet pressure data from the 2010 and 2013 tests, with and without acoustic floor treatment (hard floor). As can be seen in Figs. 9a and 9b, the flap data show no effect from acoustic treatment. However, the pressure magnitude on the upper surface of the main wing in the leading edge region shows a pronounced decrease with the acoustically-treated floor in place (test 604, acoustic floor), especially at the inboard wing location shown in Fig. 9a. Since the steady pressures are directly correlated with lift, clearly the lift loss seen in the force data is due to the change in leading edge steady pressures on the main wing. The pressures at the outboard wing location presented in Fig. $9 \mathrm{~b}$ show a similar trend, but to a lesser extent. Figure 10 shows flap surface pressures for the most inboard row (row 1) and the most outboard row (row 11). Except for two locations on the flap bottom surface at row 11 (damaged ports), the tip pressures are nearly identical for both tunnel entries. The instrumented tips were not installed during the PIV part of Test 604, so pressures are not shown for T604 with the hard floor. It is evident from Figs. 9 and 10 that, despite the reduction in wing lift, the floor acoustic treatment did not affect the steady loading across the flap span, in particular at the inboard and outboard tips where flap noise sources reside.

Fuselage pressure coefficients at $\alpha=3^{\circ}$ measured during the 2010 and 2013 tests are now compared. For reference purposes, pressure port locations are given in Fig. 11. Note from Fig. 12 that the flow over portions of the fuselage near the top (near $180^{\circ}$, rows 1 and 2) and wing junction (row 3) is slower (less negative $\mathrm{C}_{\mathrm{p}}$ ) with the acoustic flooring installed than with the hard floor. The most likely cause of kinetic energy losses in these areas is a thickening of the floor boundary layer produced by the acoustic treatment. This supports the conclusion that the rough, acoustically-treated floor had a measurable effect on the model lift.

12

American Institute of Aeronautics and Astronautics 


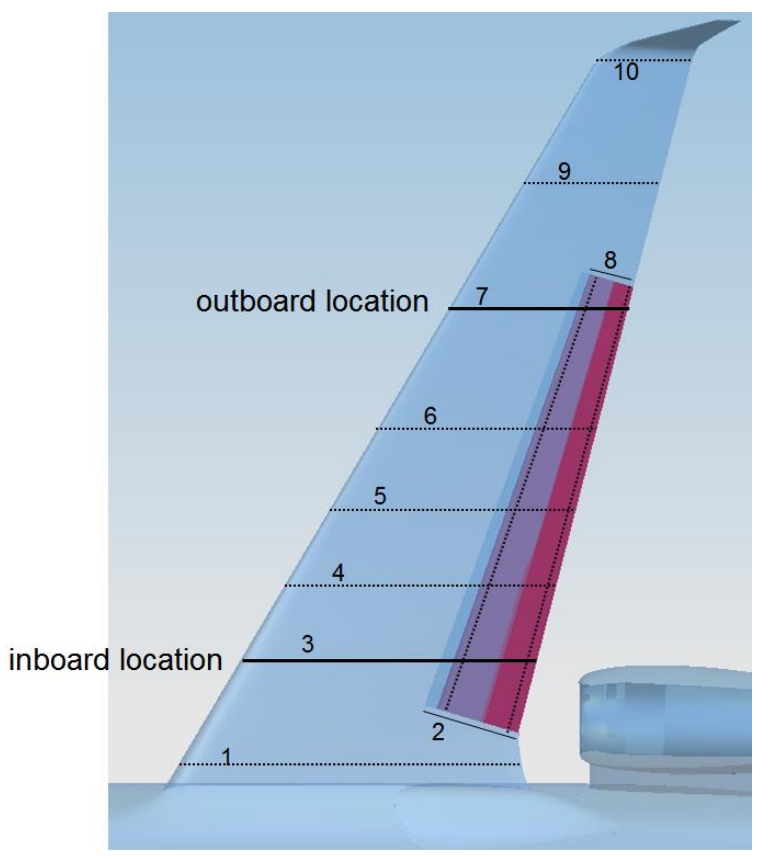

a) Wing pressure row locations.

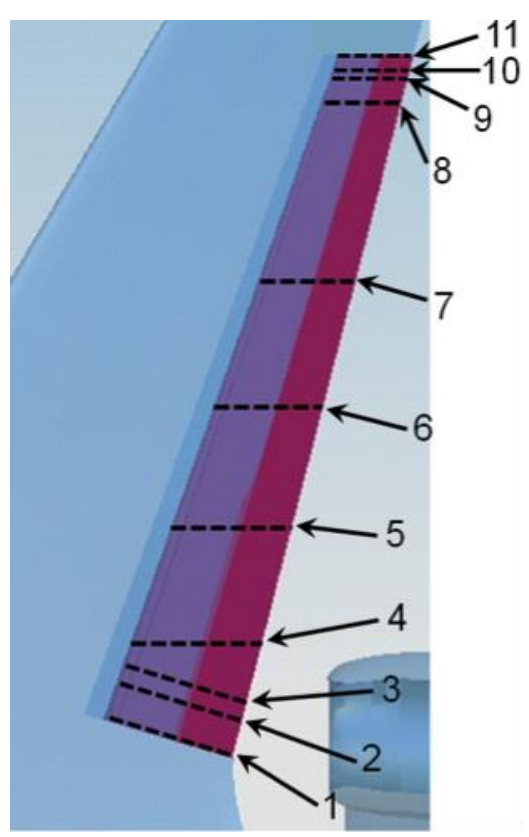

b) Flap pressure row locations.

Figure 8. Wing and flap steady pressure row locations. 

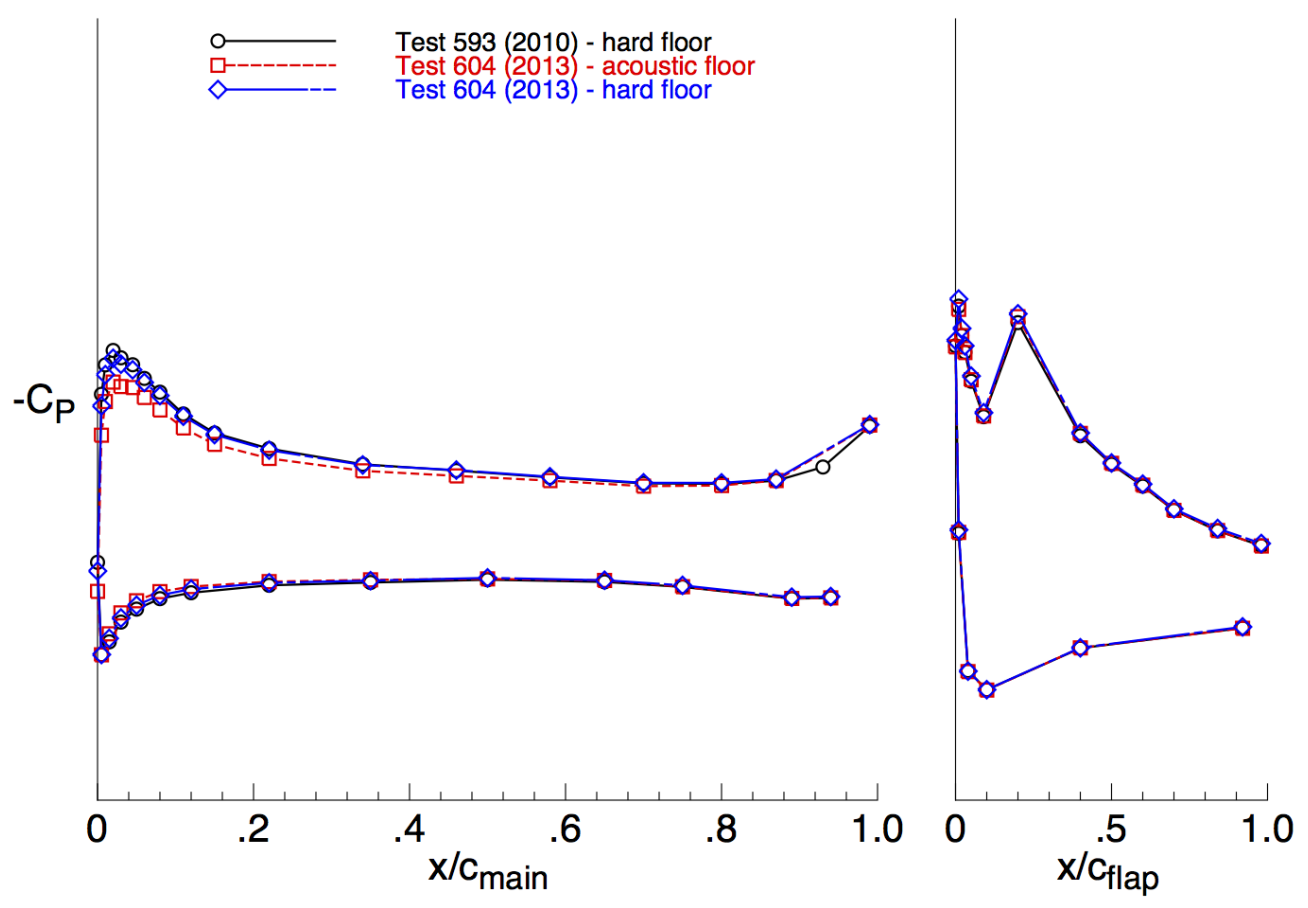

a) Inboard wing location, landing gear on, flaps $39^{\circ}$.
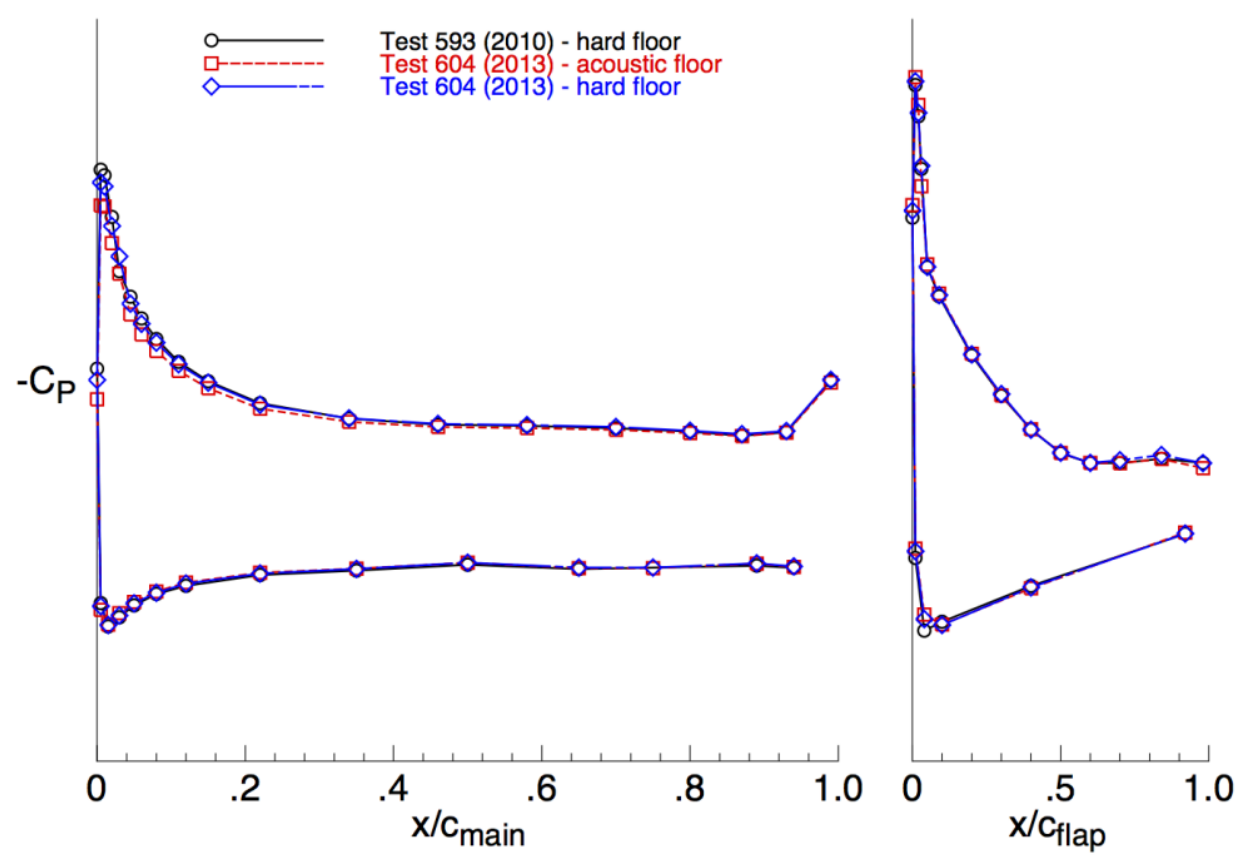

b) Outboard wing location, landing gear on, flaps $39^{\circ}$.

Figure 9. Distribution of steady pressure coefficients at two wing locations, $\alpha=3^{\circ}$. 


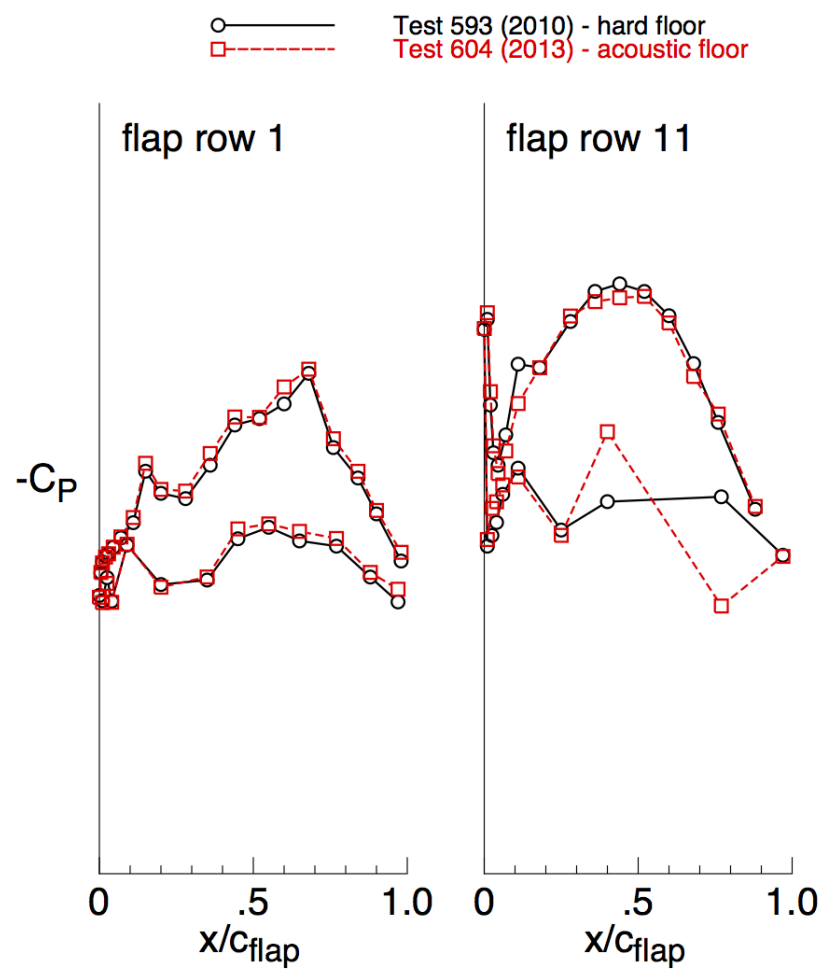

Figure 10. Distribution of steady pressure coefficients at two flap locations, $\alpha=3^{\circ}$, landing gear on, flaps $39^{\circ}$.

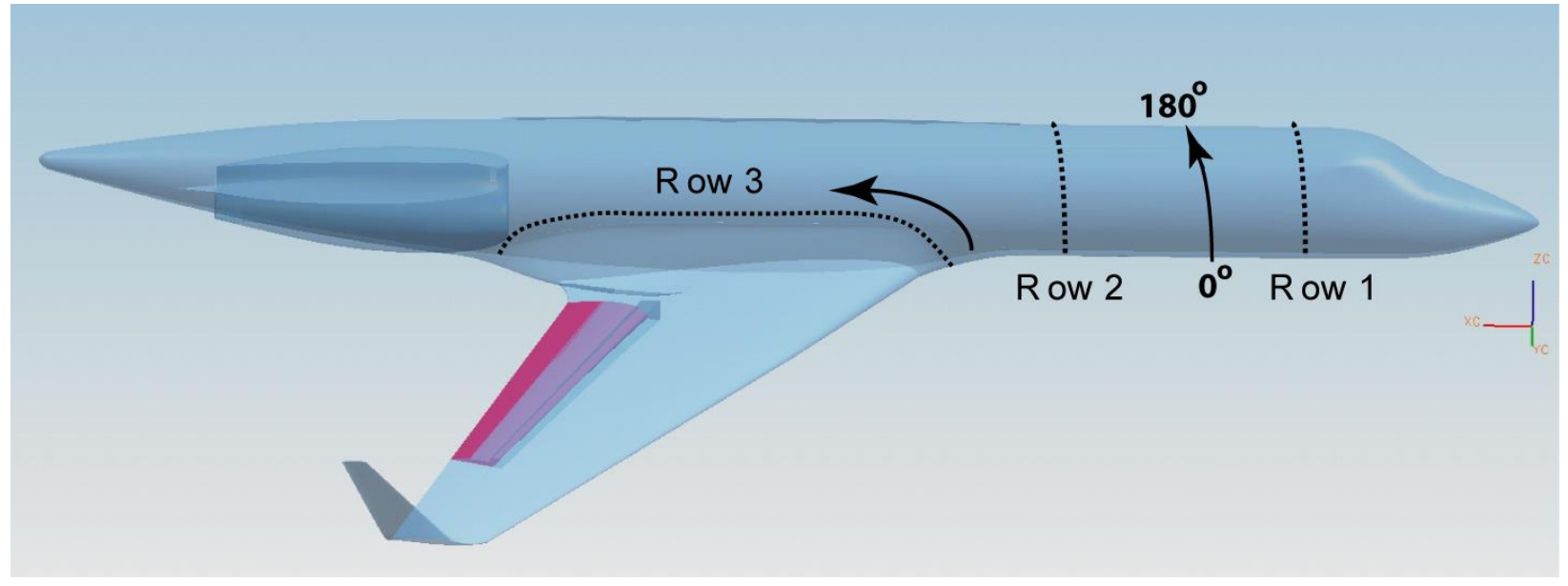

Figure 11. Fuselage pressure row locations. 


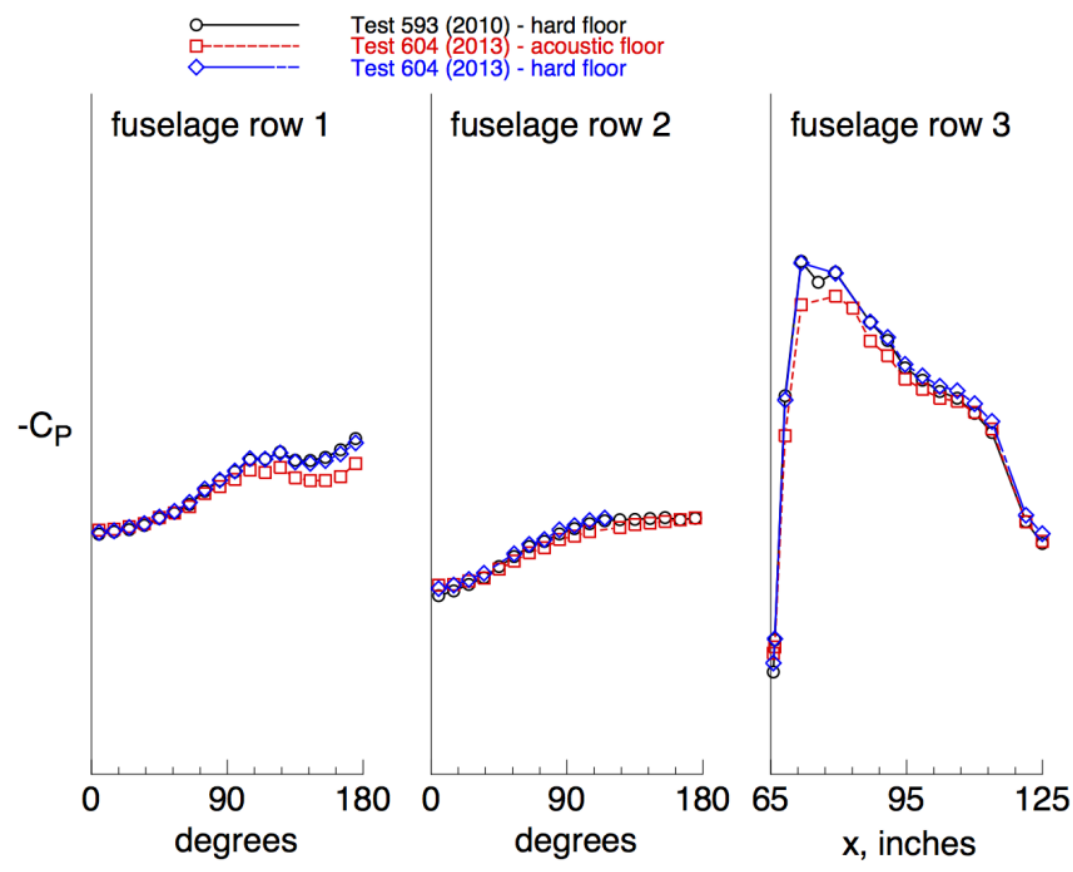

Figure 12. Distribution of steady pressure coefficients at fuselage row locations, $\alpha=3^{\circ}$.

\section{Unsteady Surface Pressures}

A substantial component of airframe noise is that produced by the unsteady flow around the flap side edges. An examination was made of the unsteady surface pressures in the vicinity of the flap edges to determine if the fluctuating local flow field containing the noise sources was affected by the acoustically treated floor.

The quantities calculated from the measured unsteady pressures were the power spectral density (PSD), the RMS (root mean square) pressure coefficient, $\mathrm{Cp}_{\text {rms }}^{\prime}$, and the coherence. Uncertainties in these calculated quantities were estimated to be the following: $\mathrm{U}_{\mathrm{PSD}} / \mathrm{PSD}=0.12(12 \%), \mathrm{U}_{\mathrm{Cp} r m s} / \mathrm{Cp}_{\mathrm{rms}}^{\prime}=0.06(6 \%)$, and for coherence, the uncertainty varies as shown in Table 1.

Table 1. Uncertainty associated with computed coherence

\begin{tabular}{|c|c|}
\hline Coherence & $\underline{\mathbf{U}}_{\text {coh }}$ \\
\hline 1 & 0 \\
\hline 0.75 & 0.04 \\
\hline 0.5 & 0.1 \\
\hline 0.25 & 0.21 \\
\hline 0 & infinite \\
\hline
\end{tabular}

Unsteady pressure data (RMS pressure coefficients) are shown in Fig. 13 for selected sensors at the flap midspan, and inboard and outboard tips. As before, comparisons are made between the 2010 open-jet data with the hard floor and the corresponding results from the 2013 test with the acoustic floor treatment. (No unsteady flap tip data are available for the 2013 hard floor runs because the flap tips were not instrumented during those runs). Sensors that failed either before or during the 2013 test are at "0" on the plot. For both the inboard and outboard flap tips, for the majority of the sensors, the data compare well, implying that no significant effect of the wing lift loss is apparent in the unsteady pressure data on the flap. Except for a few sensors, primarily on the outboard flap tip, most of the 
coefficient values are within the uncertainty estimate (shown by error bars) for this parameter. This provides additional support to the assertion that the flap edge noise source regions were not affected by the acoustic floor treatment.

A more detailed look at the unsteady data can be made by examining plots of the power spectral density (PSD), from which the RMS pressure coefficients were derived. All PSD plots in this paper show PSD versus model-scale frequency. Figures 14a and 14b show the locations of sensors on the flap inboard and outboard edges, respectively. PSD versus frequency is presented for several selected flap inboard and outboard tip sensors, for the 2010 and 2013 tests, in Fig. 15. Figure 15a shows the spectra for the inboard flap tip on the side edge wall (sensor 10). The spectra for the inboard tip on the flap top edge (sensor 2) are shown in Fig. 15b. Figure 15c shows the spectra for the outboard flap tip on the side edge wall inside the tip cavity (sensor 27). Finally, the spectra for the outboard flap tip on the flap top edge (sensor 28) are shown in Fig. 15d. In all cases, the differences in spectra are minimal and the character of the spectra (shapes, intensity levels, and frequency content) is preserved, indicating that the noise sources were not affected by the configuration of the test chamber floor - acoustically hard (2010 data) or acoustically soft (2013 data).

The coherence between sensors 2 and 10 at the flap inboard edge for the two tests is shown in Fig.16. These two sensors were the most coherent of the inboard flap edge sensors, indicating that the vortex formed on the flap inboard side-edge wall likely moved over the edge, very close to sensor 2 . The differences below $100 \mathrm{~Hz}$ are well within uncertainty levels; above $100 \mathrm{~Hz}$, the coherence is effectively equal for both tests. These two sensors had a linear phase relationship (constant time delay between sensors) out to about $2 \mathrm{kHz}$ and the phase relationship was essentially identical for both tests (phase was examined separately and not shown in this paper). Clearly, the relationship between these two sensors near the tunnel floor (inboard flap edge location) is generally unaffected by the floor configuration. The coherence between nearby sensors 4 and 10 (not shown) was very similar.

Selected power spectra will be shown for the strut, wheel, and door of the landing gear to examine any effect of the acoustic floor treatment. Figure 17 shows a photograph of the main landing gear in the baseline configuration, i.e., with no noise reduction concepts installed. The strut sensors will be examined first by looking at the spectra for two locations on the rear strut, sensors 40 and 42 , (Fig. 18), located at $135^{\circ}$ and $290^{\circ}$, facing downstream and upstream, respectively. Figure 19a shows the spectra for the downstream-facing rear strut sensor. The spectra are clearly very close to each other. In Fig. 19b, the spectra for the upstream-facing rear-strut sensor is provided, showing the same close agreement. Sensors 40 and 42 represent the lowest and highest levels of spectra on the strut, respectively, and in neither case is the effect of the acoustic floor treatment evident.

Figure 20 shows a diagram of the inner view of the main landing gear wheels. The spectra from two sensors will be examined, the wheel outer shoulder sensors 45 (inner wheel) and 50 (outer wheel). The spectra for these two sensors are shown in Figs. 21a and 21b, respectively. As with the strut spectra above, the two sets represent a lower and higher spectral level. The higher level, especially at higher frequencies, for the outer wheel shoulder sensor, sensor 50, Fig. 21b, is presumably due to the close proximity of the door to that wheel. Again, no significant effect of the tunnel floor acoustic treatment is evident, regardless of sensor location or spectral level.

A diagram of the landing gear door is presented in Fig. 22. Sample spectra at two sensor locations are examined, one in the center of the door (sensor 56) and one at the leading edge (upstream, sensor 59). Sensor 59 had a considerably higher spectral level (Fig. 23a) and RMS pressure coefficient level (about 2.5 times, not shown here), than the center-door sensor (56, Fig. 23b). In general, the fluctuating pressures recorded on the door were nearly two orders of magnitude lower than those obtained on the flap or other gear components. For this aircraft model, the gear door is not a major noise source and mostly acts as a reflector of the impinging acoustic waves produced at other locations on the model. At the two sensor locations shown, a tone at $230 \mathrm{~Hz}$ is observed and it is due to the acoustic resonance from the gear cavity. The origin of this tone was discovered by covering the cavity and noticing the

17

American Institute of Aeronautics and Astronautics 
disappearance of the peak. The sensor at the door center reveals a $2 \mathrm{kHz}$ tone proven to radiate from the front-strutknee opening, and a third tone, centered between $2.3 \mathrm{kHz}$ and $2.75 \mathrm{kHz}$, is likely the result of vortex shedding from the flap and wing trailing edges in the vicinity of the inboard edge.

Based on close examination of the steady and unsteady pressure fields on critical components of the model, it became clear to us that the distribution and character of the noise sources remained unchanged due to the tunnel floor acoustic treatment, allowing the acoustic measurement phase of the test to proceed.

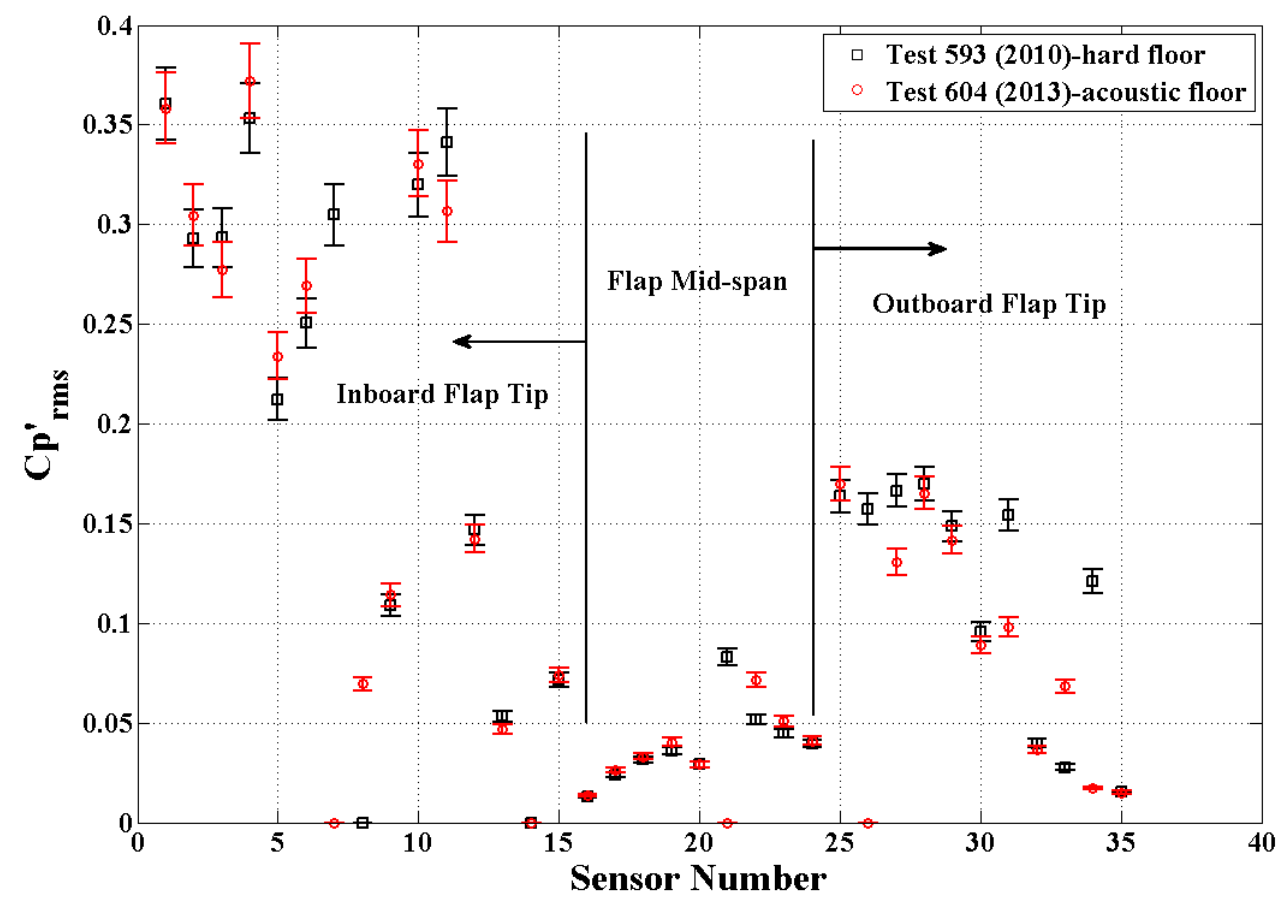

Figure 13. Unsteady RMS pressure coefficients for inboard and outboard flap tips.

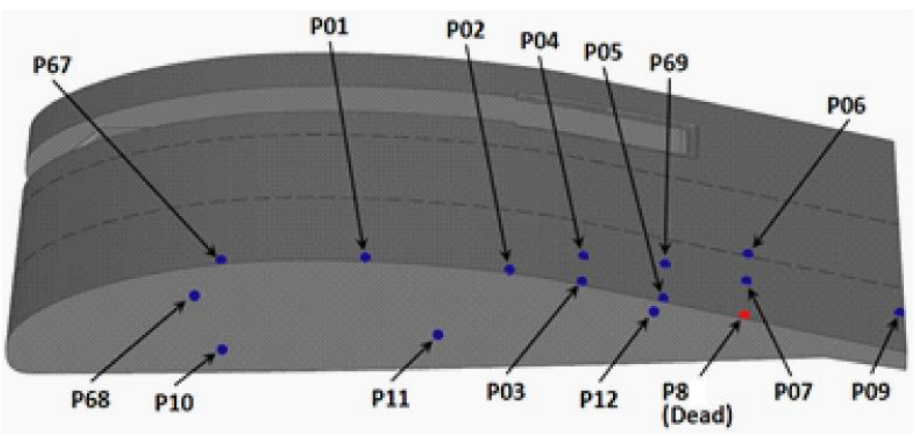

Figure 14a. Locations and numbering of probes installed at flap edges-inboard edge. 


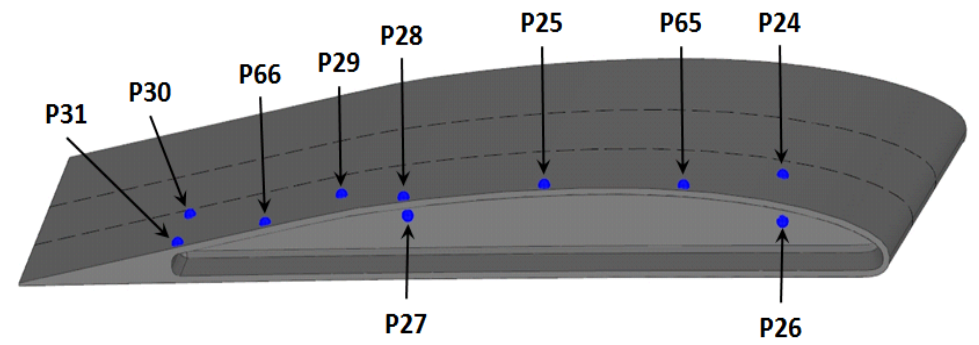

Figure 14b. Locations and numbering of probes installed at flap edges-outboard edge.

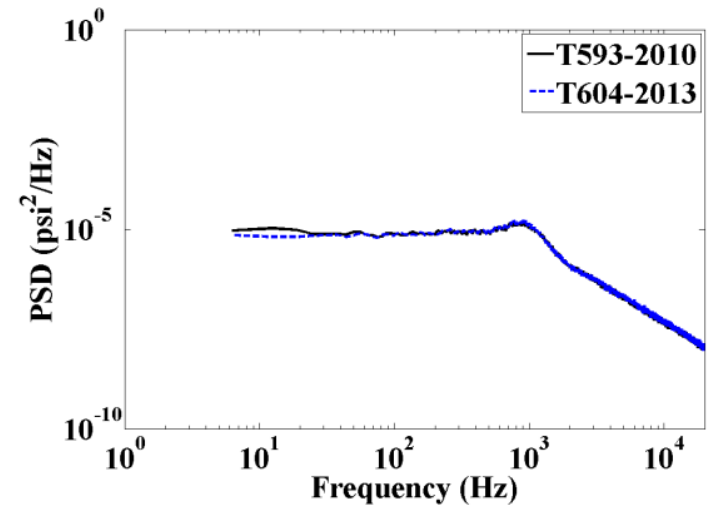

a) Flap inboard tip, side edge wall (sensor 10).

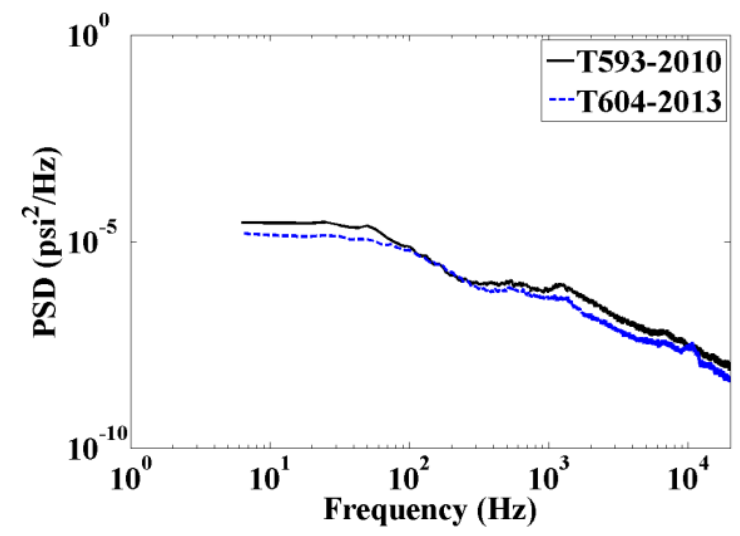

c) Flap outboard tip, side edge (sensor 27).

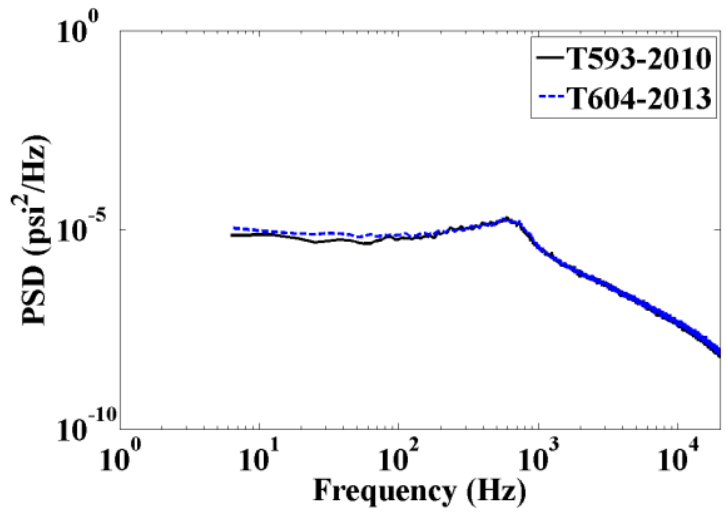

b) Flap inboard tip, top edge (sensor 2).

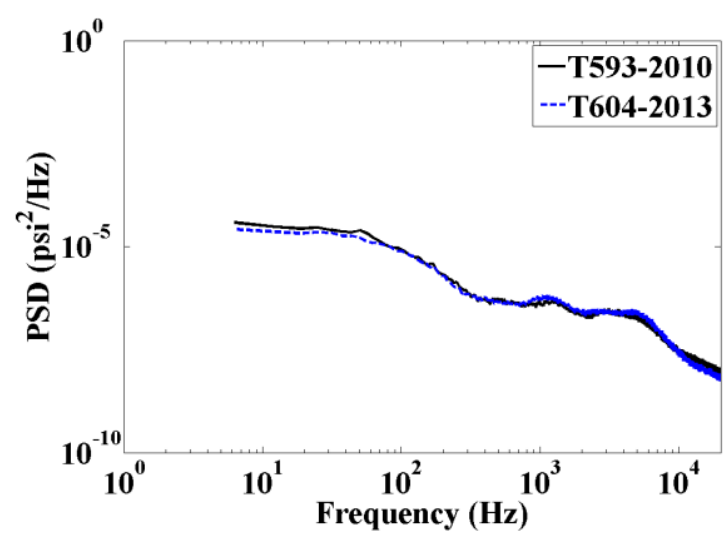

d) Flap outboard tip, top edge (sensor 28).

Figure 15. Power spectral density-flap tips-2010 vs. 2013 tests. 


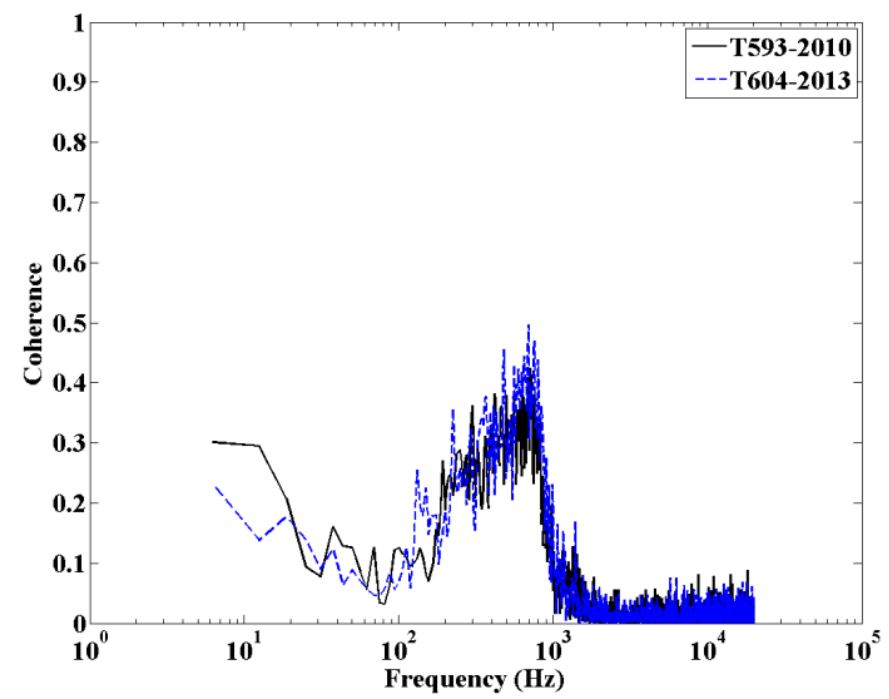

Figure 16. Coherence between channels 2 and 10-2010 vs. 2013 tests.

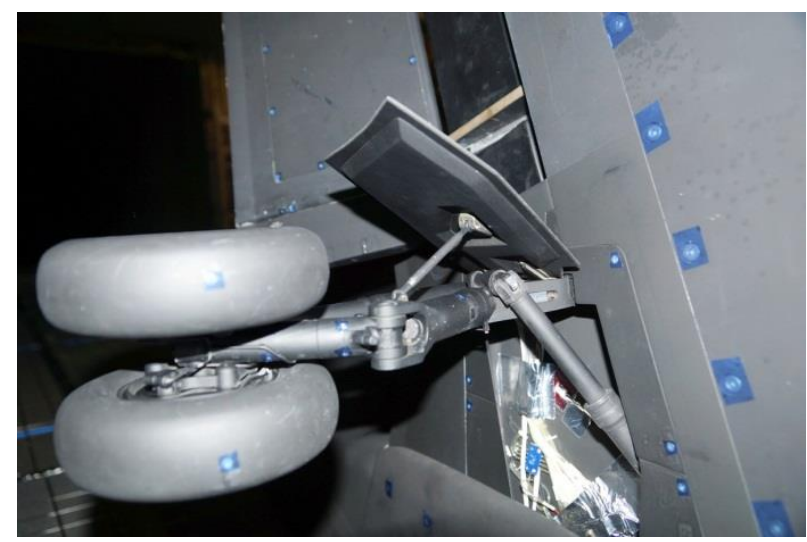

Figure 17. Frontal view of the $18 \%$ main landing gear without noise reduction concepts installed (baseline).

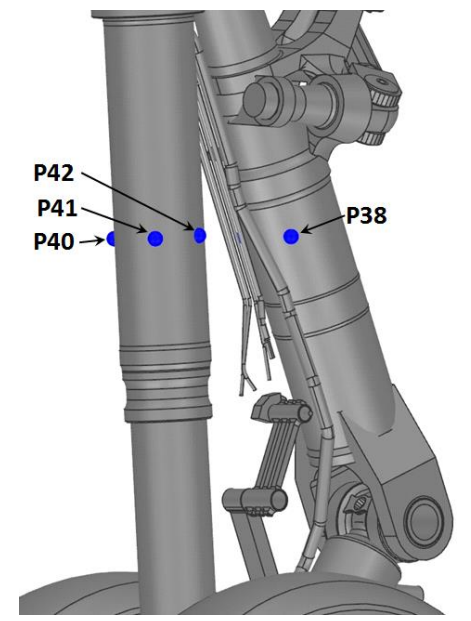

Figure 18. Interior (fuselage) view of main struts. 


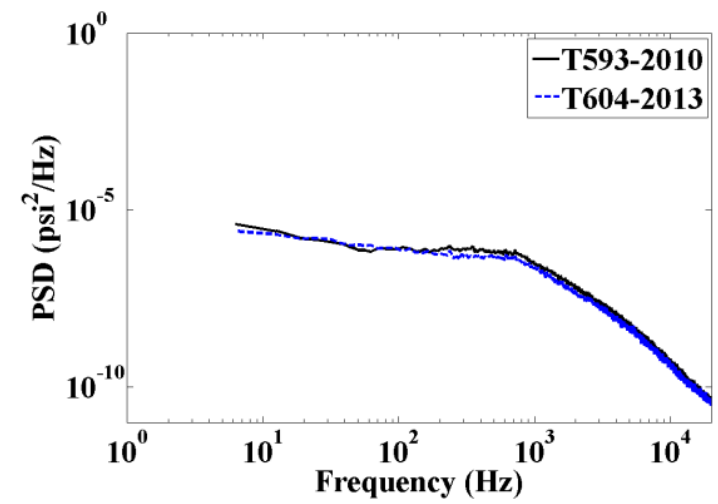

a) Sensor at $135^{\circ}$ (rear-facing, sensor 40).

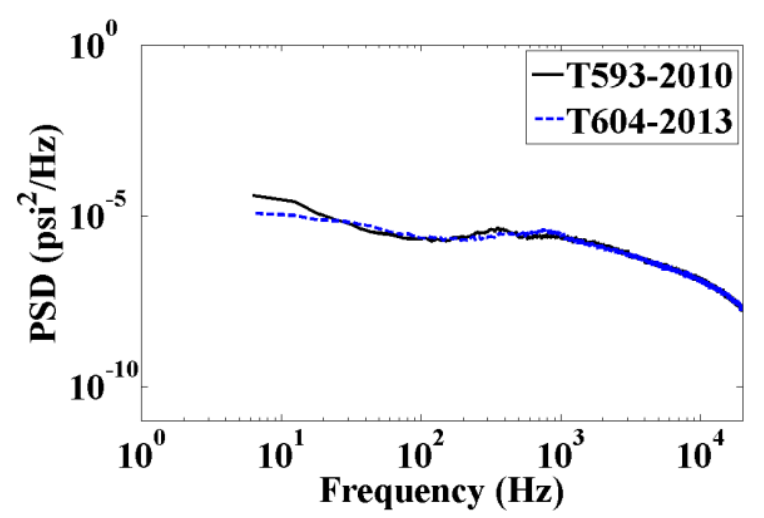

b) Sensor at $290^{\circ}$ (forward-facing, sensor 42 ).

Figure 19. Power spectral density-rear strut-2010 vs. 2013 tests.

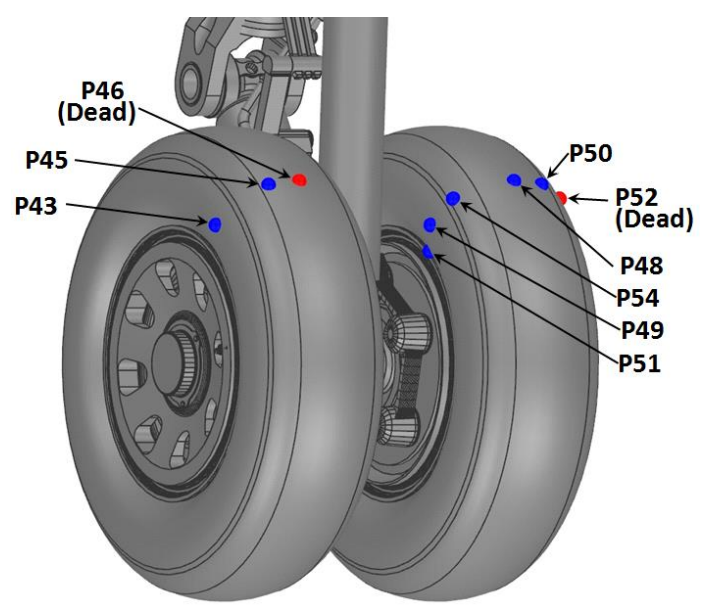

Figure 20. Interior (fuselage) view of the wheels showing the locations of the installed sensors.

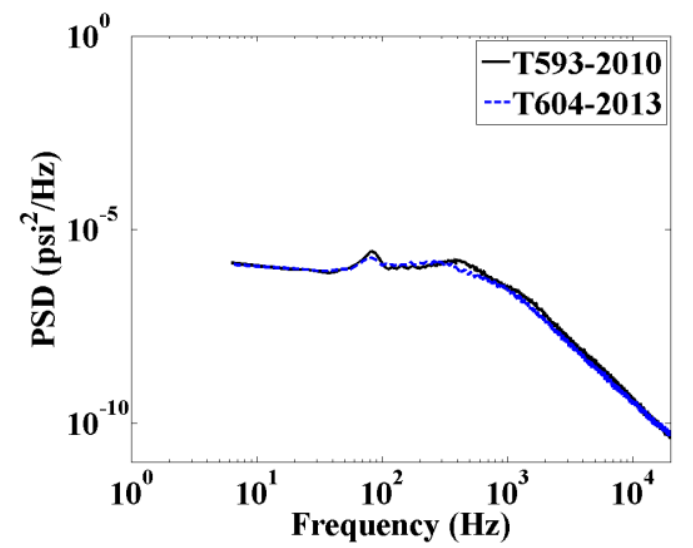

a) Sensor at inner wheel shoulder (sensor 45).

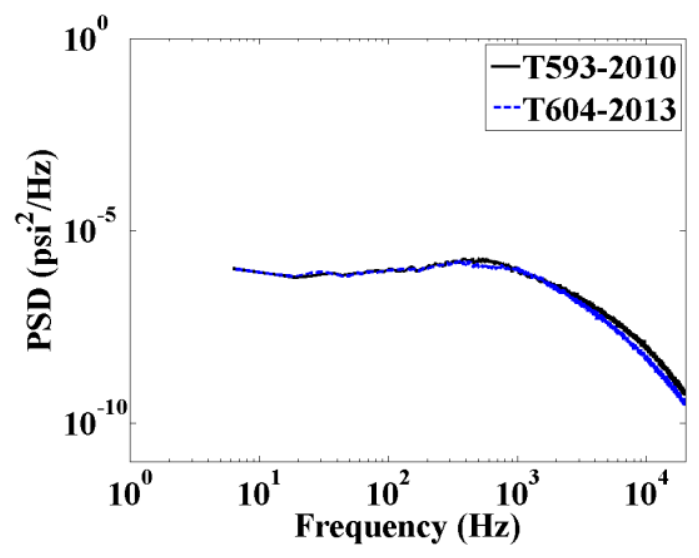

b) Sensor at outer wheel shoulder (sensor 50).

Figure 21. Power spectral density-wheels-2010 vs. 2013 tests. 


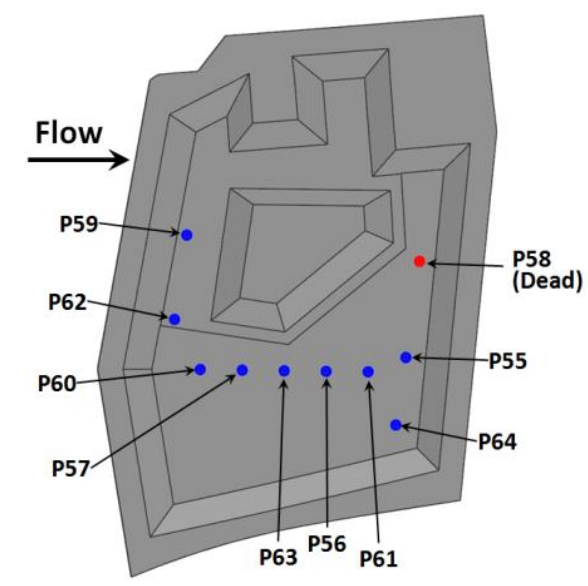

Figure 22. Door interior side.

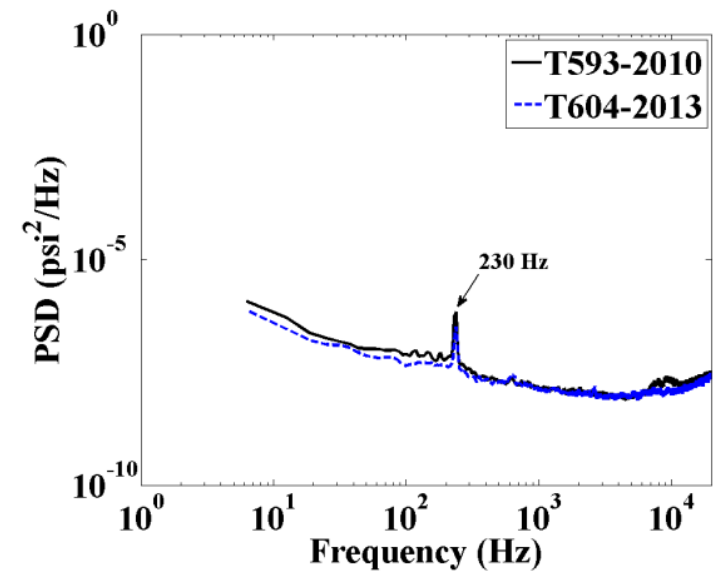

a) Sensor at leading edge of door (sensor 59).

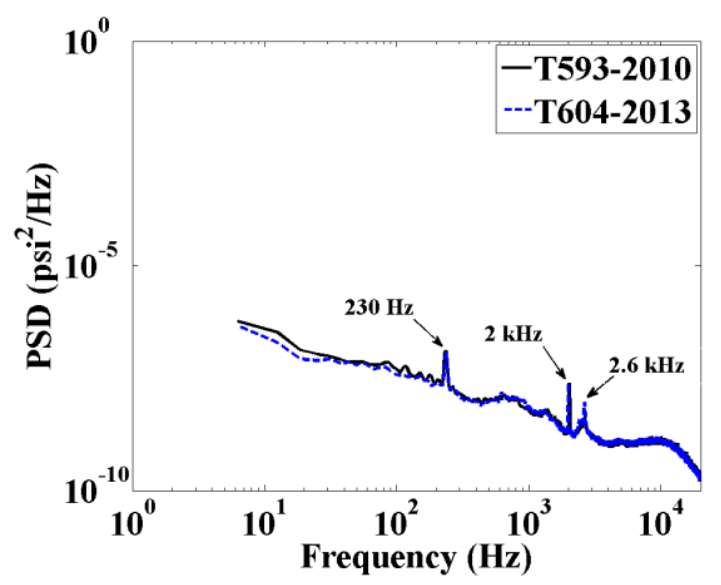

b) Sensor at center of door (sensor 56).

Figure 23. Power spectral density-landing gear door-2010 vs.2013 tests.

\section{Concluding Remarks}

Steady and unsteady aerodynamic measurements of a high-fidelity, semi-span $18 \%$ scale Gulfstream aircraft model were collected concurrently with acoustic measurements as part of a larger aeroacoustic study targeting airframe noise associated with main landing gear/flap components, gear-flap interaction noise, and the viability of related noise mitigation technologies. The aeroacoustic tests were conducted in the NASA Langley Research Center 14- by 22-Foot Subsonic Wind Tunnel with the facility in the acoustically treated open-wall (jet) mode. Most of the measurements were obtained with the model in landing configuration with the flap deflected at $39^{\circ}$ and the main landing gear on and off. Data were acquired at Mach numbers of 0.16, 0.20, and 0.24. Global forces (lift and drag) and extensive steady and unsteady surface pressure measurements were obtained. 
Comparison of the present results with those acquired during a previous test showed a measurable reduction in the lift produced by the model. The underlying cause was thought to be related to a thicker boundary layer on the tunnel floor, which was acoustically treated for the present test. Examination of the pressure distributions on the wing nearest the floor substantiates this conclusion by showing reduced upper surface pressure levels. Steady pressures on the fuselage near the tunnel floor corroborated the reduced lift by indicating slower flow in these areas. Repeatability analyses for the aeroacoustic test (acoustic floor) and the PIV test (hard floor) confirm that the differences in $C_{L}$ and $C_{D}$ are statistically significant and outside of the scatter for each individual test.

On the flap, the steady and unsteady pressure fields, particularly in the regions of predominant noise sources such as the inboard and outboard tips, remained unaffected by the acoustic floor treatment. Specifically, power spectra, RMS pressure coefficients, and coherence between correlated unsteady pressure sensors show no effect of the floor configuration. Additional examination of spectra on the landing gear struts, wheels, and door at selected representative sensors show very similar spectral levels between the two test entries, further substantiating the conclusion that the acoustic floor treatment had no significant effect on unsteady flow characteristics, including regions of predominant noise sources.

It is shown that the changes in lift and drag coefficients for model configurations fitted with gear/flap noise abatement technologies fall within the repeatability of the baseline configuration. Therefore, the noise abatement technologies evaluated in this experiment have no detrimental impact on the aerodynamic performance of the aircraft model.

\section{Acknowledgment}

This work was supported by the Environmentally Responsible Aviation (ERA) project under the Integrated System Research Program (ISRP) of NASA. We would like to thank the staff of the Langley $14 \times 22$ facility for their outstanding support and execution of a highly productive test entry.

\section{References}

1. Michel, U., Barsikow, B., Helbig, J., Hellmig, M., and Schüttpelz, M., "Flyover Noise Measurements on Landing Aircraft with Microphone Array", AIAA Paper 98-2336, May 1998.

2. Piet, J.-F., Elias, G., and Lebigot, P., "Localization of Acoustic Sources from a Landing Aircraft with a Microphone Array," AIAA Paper 99-1811, May 10-12, 1999

3. Michel, U., and Qiao, W., "Directivity of Landing-Gear noise Based on Flyover Measurements". AIAA-99-1956, May 10-12, 1999.

4. Pott-Pollenske, M., Dobrzynski, W., Buchholz, H., Gehlhar, B., Walle, F., "Validation of a Semiempirical Airframe Noise Prediction Method through Dedicated A319 Flyover Noise Measurements", AIAA Paper 2002-2470, May 2002.

5. Stoker, R., Guo, Y., Streett, C., and Burnside, N., "Airframe Noise Source Locations of a 777 Aircraft in Flight and Comparisons with Past Model Tests,” AIAA Paper 2003-3232, May, 2003.

6. Sijtsma, P. and Stoker, R., "Determination of Absolute Contributions of Aircraft Noise Components Using Fly-Over Array Measurements," AIAA paper 2004-2958, May, 2004,.

7. Piet, J-F, Davy, R., Elias, G. and Siller, H. A., Chow, L.C., Seror, C., and Laporte, F., "Flight Test Investigation of Add-On Treatments to Reduce Aircraft Airframe Noise,” AIAA Paper 2005-3007, May, 2005.

8. Horne, W. C., James, K. D., Arledge, T. K., Soderman, P. T., Burnside, N., and Jaeger, S. M., "Measurements of 26\%-Scale 777 Airframe Noise in the NASA Ames 40- by 80-Foot Wind Tunnel," AIAA Paper 2005-2810, May 2005. 
9. Elkoby, R., Brusniak, L., Stoker, R., Khorrami, M.R., Abeysinghe, A., and Moe, J.W., “Airframe Noise Results from the QTD II Flight Test Program,” AIAA Paper 2007-3457, May, 2007.

10. Khorrami, M. R., Lockard, D. P., Humphreys, Jr., W. M., Choudhari, M. M., and Van de Ven, T., "Preliminary Analysis of Acoustic Measurements from the NASA-Gulfstream Airframe Noise Flight Test,” AIAA Paper 2008-2814, May 2008.

11. Khorrami, M. R., Hannon, J. A., Neuhart, D. H., Markowski, G. A., and Van de Ven, T., "Aeroacoustic Studies of a HighFidelity Aircraft Model: Part 1-Steady Aerodynamic Measurements,” AIAA Paper 2012-2233, June 2012.

12. Khorrami, M. R. and Neuhart, D. H, “Aeroacoustic Studies of a High-Fidelity Aircraft Model: Part 2- Unsteady Surface Pressures,” AIAA Paper 2012-2234, June 2012.

13. Khorrami, M.R., Humphreys, W. M., Jr., Lockard, D. P., and Ravetta, P. A., "Aeroacoustic Evaluation of Flap and Landing Gear Noise Reduction Concepts," paper to be presented at the $20^{\text {th }}$ AIAA/CEAS Aeroacoustics Conference, Atlanta, GA, June, 2014.

14. Yao et al., "Flow-Field Investigation of Gear-Flap Interaction on a Gulfstream Aircraft Model," paper to be presented at the $20^{\text {th }}$ AIAA/CEAS Aeroacoustics Conference, Atlanta, GA, June, 2014.

15. Gentry, C. L., Jr., Quinto, P. F., Gatlin, G. M., and Applin, Z. T., “The Langley 14- by 22-Foot Subsonic Tunnel: Description, Flow Characteristics, and Guide for Users," NASA TP-3008, 1990.

16. Wahls, R. A., Adcock, J. B., Witkowski, D. P., and Wright, F. L., "A Longitudinal Aerodynamic Data Repeatability Study for a Commercial Transport Model Test in the National Transonic Facility," NASA TP 3522, 1995.

17. Hemsch, M. J. and Houlden, H. P., "Repeatability Modeling for Wind-Tunnel Measurements: Results for Three Langley Facilities," AIAA Paper 2014-0096, January, 2014. 